OPEN ACCESS

Edited by: Philippa Warren, King's College London, United Kingdom

Reviewed by:

Leon Teo,

Australian Regenerative Medicine Institute (ARMI), Australia Kinga Szydlowska,

Nencki Institute of Experimental Biology (PAS), Poland

${ }^{*}$ Correspondence: Bin Ning ningbin@sdu.edu.cn

Specialty section:

This article was submitted to Cellular Neuropathology, a section of the journal Frontiers in Cellular Neuroscience

Received: 11 October 2021 Accepted: 07 December 2021 Published: 23 December 2021

Citation:

Yu G, Zhang $Y$ and Ning $B$ (2021) Reactive Astrocytes in Central Nervous System Injury: Subgroup and Potential Therapy. Front. Cell. Neurosci. 15:792764. doi: 10.3389/fncel.2021.792764

\section{Reactive Astrocytes in Central Nervous System Injury: Subgroup and Potential Therapy}

\author{
GuiLian Yu, Ying Zhang and Bin Ning* \\ Jinan Central Hospital, Cheeloo College of Medicine, Shandong University, Jinan, China
}

Traumatic central nervous system (CNS) injury, which includes both traumatic brain injury (TBI) and spinal cord injury (SCl), is associated with irreversible loss of neurological function and high medical care costs. Currently, no effective treatment exists to improve the prognosis of patients. Astrocytes comprise the largest population of glial cells in the CNS and, with the advancements in the field of neurology, are increasingly recognized as having key functions in both the brain and the spinal cord. When stimulated by disease or injury, astrocytes become activated and undergo a series of changes, including alterations in gene expression, hypertrophy, the loss of inherent functions, and the acquisition of new ones. Studies have shown that astrocytes are highly heterogeneous with respect to their gene expression profiles, and this heterogeneity accounts for their observed context-dependent phenotypic diversity. In the inured CNS, activated astrocytes play a dual role both as regulators of neuroinflammation and in scar formation. Identifying the subpopulations of reactive astrocytes that exert beneficial or harmful effects will aid in deciphering the pathological mechanisms underlying CNS injuries and ultimately provide a theoretical basis for the development of effective strategies for the treatment of associated conditions. Following CNS injury, as the disease progresses, astrocyte phenotypes undergo continuous changes. Although current research methods do not allow a comprehensive and accurate classification of astrocyte subpopulations in complex pathological contexts, they can nonetheless aid in understanding the roles of astrocytes in disease. In this review, after a brief introduction to the pathology of CNS injury, we summarize current knowledge regarding astrocyte activation following CNS injury, including: (a) the regulatory factors involved in this process; (b) the functions of different astrocyte subgroups based on the existing classification of astrocytes; and (c) attempts at astrocyte-targeted therapy.

Keywords: traumatic brain injury, spinal cord injury, reactive astrocytes, scar-forming astrocytes, astrocytetargeted therapy

\section{INTRODUCTION}

In 1856, Rudolf Virchow described for the first time a type of cell with neuron-supportive functions (Virchow, 1856). Then, in 1895, MV Lenhossék proposed the name astrocyte (“Astrocyten") for this type of neuron-supporting cell (Lenhossék, 1893). Cortical astrocytes originate from radial glia derived from the neuroepithelial cells, radial glial cells originate from the cortical ventricular zone and are characterized by a long basal process that extends from the cortical ventricular zone 
to the pial surface (Arellano et al., 2021). During embryonic development, radial glial cells generate intermediate glial progenitors via asymmetric division, and these progenitors then migrate, proliferate, and finally transform into astrocytes in nerve tissue. After birth, astrocytes are primarily generated through the direct transformation of radial glial cells in the ventricular zone, the migration and development of postnatal progenitors in the subventricular zone, and the symmetrical division of differentiated astrocytes (Levison and Goldman, 1993; Ge et al., 2012; Verkhratsky and Nedergaard, 2018; Abdeladim et al., 2019). NG2 glial cells comprise another possible source of astrocytes (Nishiyama et al., 2016). Here, astrocytes undergo limited migration along with radial glial processes (Jacobsen and Miller, 2003). Astrocytes of different origins are phenotypically diverse, which is a partial manifestation of the heterogeneity of astrocyte morphology and function (Magavi et al., 2012; Tsai et al., 2012; Molofsky and Deneen, 2015). A combination of heredity, development, and phenotype renders astrocytes a truly opportunistic cell with lifelong adaptive plasticity.

Under physiological conditions, astrocytes perform a variety of functions primarily associated with the maintenance of CNS homeostasis, including the formation and maintenance of the blood-brain barrier (BBB) and blood-spinal cord barrier (BSCB), signal transmission across synapses, the maintenance of neuronal function, and metabolic regulation (Molofsky and Deneen, 2015). In a pathological background, however, astrocytes can become activated. The lifelong adaptive plasticity of these cells and the complexity of the disease background determine the diversity of astrocyte subpopulations after injury (Verkhratsky and Nedergaard, 2018). Following CNS insult, activated astrocytes can sequentially display two different histological phenotypes over time, first becoming reactive astrocytes (RAs), and then scar-forming astrocytes (SAs; Hara et al., 2017). This sequential phenotypic change from the resting state to the activated state is referred to as reactive astrogliosis (Zamanian et al., 2012). However, this histological classification method fails to clearly define RAs and SAs as it is neither objective nor quantitative.

In 2017, Hara et al. (2017) were the first to define several RA- and SA-specific marker genes in the mouse. Plaur, Mmp2, Mmp13, Axin2, Nes, and Ctnnb1 were classified as RA marker genes, while SA markers included Cdh2, Sox9, and chondroitin sulfate proteoglycan (CSPG)-related genes, such as Xylt1, Csgalnact1, Chst11, Pcan, Acan, and Slit2. Nevertheless, RAs and SAs both display high expression levels of several proteins, including GFAP, nestin, $\beta$-catenin, $\mathrm{N}$ cadherin, and SOX9. As the disease progresses, there is an overlap of RA subpopulations and RAs interact with Coll and are converted into SAs via the integrin/N-cadherin pathway (Hara et al., 2017; Li X. et al., 2020). This research is of great significance to the understanding of SAs, but due to the lack of further research, the function of SA is not yet clear. Recently, Escartin et al. (2021) redefined RAs as 'astrocytes that undergo molecular, morphological, and functional changes in response to pathological stimuli from surrounding tissue, such as CNS disease, injury, and deleterious experimental manipulation, among others. High GFAP expression levels and cell hypertrophy are considered the minimum criteria for defining RAs (Liddelow et al., 2017).

In addition to the above classification of astrocytes (RAs and SAs), RAs are also divided into different astrocyte subgroups. In 2012, Zamanian et al. undertook a genomic analysis using two mouse injury models (inflammation and cerebral ischemia models) to profile RA phenotypes. The authors found that the RA phenotype was dependent on the type of inducing injury, and identified high Lcn2 and Serpina3n expression levels as strong markers of RA phenotype (Zamanian et al., 2012). In 2017, Liddelow et al. found that neurotoxic RAs, which they named A1 astrocytes, were induced by cytokines (TNF- $\alpha$, IL$1 \alpha$, and complement component $\mathrm{C} 1 \mathrm{q}$ ) secreted by activated microglia, whereas neuroprotective RAs, termed A2 astrocytes, were induced under ischemic and hypoxic conditions. As shown in Figure 1. The neurotoxic effect of complement component 3 (C3), a strong marker of A1 astrocytes, has been confirmed in a variety of CNS diseases, especially the interaction between the C3 cleavage fragment, C3a, and its receptor, C3aR, on neurons (Guo et al., 2010; Lian et al., 2015; Li J. et al., 2020; Yadav et al., 2021). However, the A1 and A2 phenotypes were not proposed to be universal or all-encompassing, they were widely misinterpreted as evidence for a binary polarization of reactive astrocytes in either neurotoxic or neuroprotective states, which could be readily identified in any CNS disease, acute or chronic, like the once-popular, but now discarded, Th1-Th2 lymphocyte and M1-M2 microglia polarization theories. Any binary classification method cannot show the diversity of astrocytes across diseases. More importantly, in mouse models of CNS damage, a RA subset was usually a mixture of $\mathrm{A} 1$ and $\mathrm{A} 2$ or pan-reactive transcripts (Das et al., 2020). So, Escartin et al. (2021) recommend moving beyond the A1-A2 labels and the misuse of their marker genes. In fact, the latest works of the original authors who studied these subtypes no longer use A1/A2. Guttenplan et al. (2021) used the induction conditions of A1 astrocytes but called the induction results neurotoxic reactive astrocytes. Hasel et al. (2021) used the term neuroinflammatory astrocyte, and used the pattern of "Y-zone X-positive astrocytes showing $\mathrm{Z}$ phenomenon" to describe the neuroinflammatory astrocyte subgroups he discovered. Based on existing knowledge, this is an ideal way of naming. However, the A1/A2 classification of RAs is still widely used.

In our opinion, under certain conditions, neurotoxic reactive astrocytes, neuroinflammatory astrocytes, and A1 astrocytes are almost the same. In vitro, neurotoxic reactive astrocytes and A1 astrocytes are induced in the same way. In the brain of LPS-induced systemic inflammation mouse model, Liddelow et al proposed the concept of A1 astrocytes, and Hasel et al. proposed various neuroinflammatory astrocyte subtypes, A1 astrocytes can be regarded as a subgroup of neuroinflammatory astrocytes. Neurotoxic reactive astrocytes emphasized function, while neuroinflammatory astrocytes emphasized background, both concepts include A1 astrocytes. At present, users of the A1/A2 concept all regard A1 as the representative of neurotoxic astrocytes and A2 as the representative of neuroprotective astrocytes. However, 


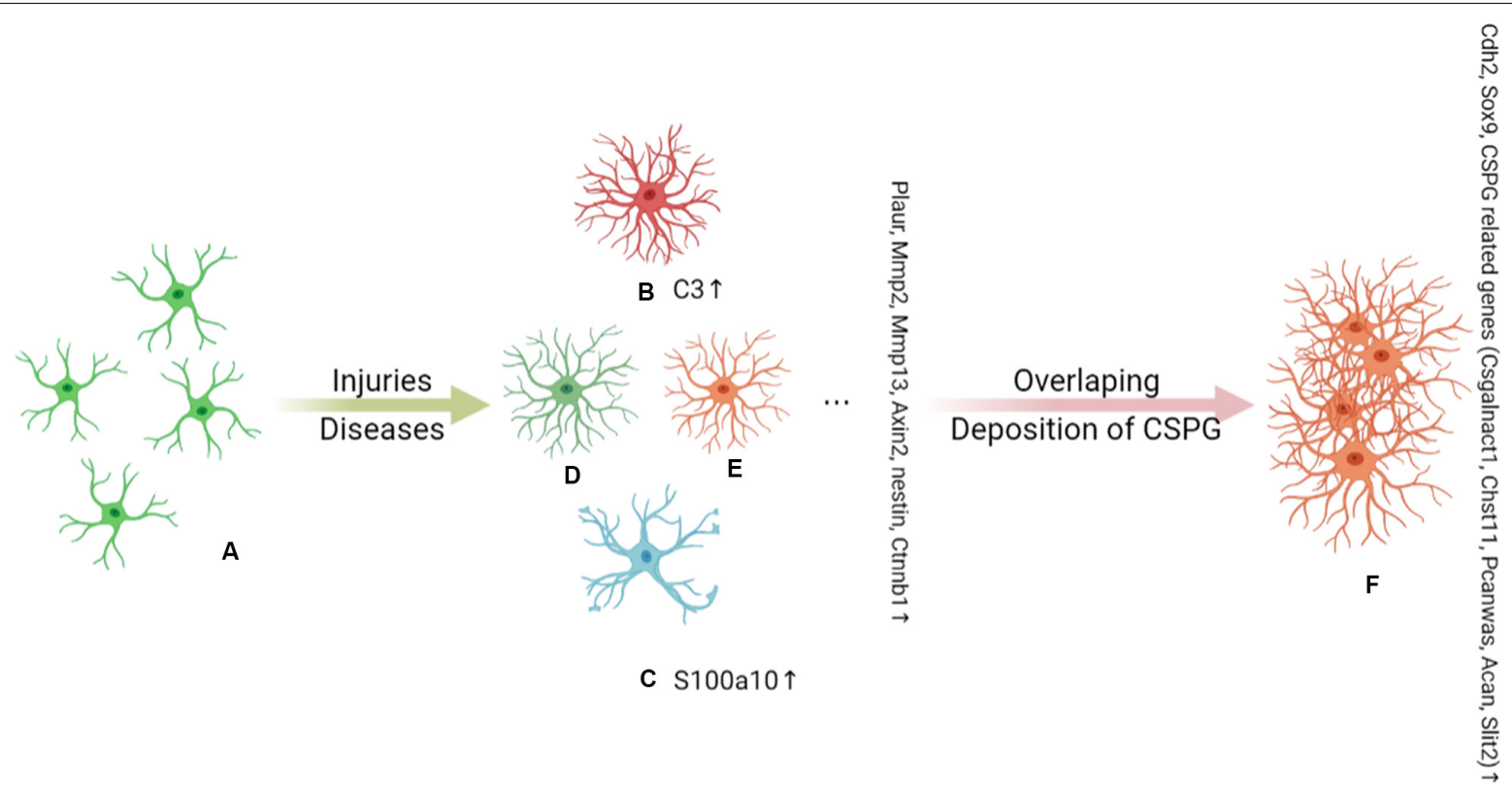

FIGURE 1 | Under the stimulation of injury and disease, (A) naive astrocytes are activated into functionally heterogeneous reactive astrocytes (RAs); this heterogeneity is determined by the background of the astrocytes. The Plaur, Mmp2, Mmp13, Axin2, Nes, and Ctnnb1 genes are markers of RAs. In an inflammatory background, (B) A1 astrocytes are proposed to be a subpopulation of neurotoxic RAs and are marked by C3 expression. (C) A2 astrocytes are induced by ischemia and hypoxia and are indicated to play a neuroprotective role in injury and disease. A2 astrocytes can be distinguished by the expression of S100A10. C3 ${ }^{+}$ A1 astrocytes have long dendrites, while $\mathrm{S} 100 \mathrm{a} 10^{+} \mathrm{A} 2$ astrocytes have hypertrophic cell bodies with few dendrites. There are other as yet unidentified subpopulations of RAs that also play an important role in disease, such as (D) and (E). As the disease progresses, there is an overlap of RA subpopulations and chondroitin sulfate proteoglycan (CSPG) deposits, which together induce the conversion of RAs to SAs (F). Cdh2, Sox9, and CSPG-related genes (Csgalnact1, Chst11, Pcan, Acan, and Slit2) are markers of scar-forming astrocytes (SAs).

considering their functional heterogeneity, it is likely that not all neurotoxic RAs are A1 astrocytes, and neither are A2 astrocytes. In the background that current knowledge does not allow objective classification of astrocytes, the use of a binary description of reactive astrocytes (A1/A2, neurotoxicity/neuroprotective), seems unavoidable. Recently, Escartin et al. (2021) reached a consensus that the field should move beyond binary descriptors and embrace objective classification based on their increasingly complex functional heterogeneity. And the work by Liddelow and Hasel supports this view (Hasel et al., 2021).

Astrocytes are key factors in secondary neuronal damage and repair inhibition largely due to their dual role in the regulation of neuroinflammation and glial scar formation after CNS injury (Liddelow and Barres, 2017; Adams and Gallo, 2018). This dual role requires the accurate classification of astrocyte subpopulations. In this review, we will focus on the heterogeneity of astrocytes and astrocyte targeted therapy strategies after CNS injuries (TBI and traumatic SCI) to help the development of targeted therapy strategies based on these precise classification of astrocytes.

\section{TRAUMATIC CNS INJURY}

Owing to the preventability of most CNS injuries and the complex and expensive medical care they require, TBI and SCI are increasingly recognized as global health priorities. In 2016, approximately 27.08 million new cases of TBI and 0.93 million new cases of SCI were diagnosed. The age-standardized incidence rate was reported to be 369 per 100,000 population for TBI and 13 per 100,000 for SCI (GBD 2016 Traumatic Brain Injury and Spinal Cord Injury Collaborators, 2019). TBI alone caused annual global economic losses of \$US400 billion (Maas et al., 2017). From 1990 to 2016, the age-standardized prevalence of TBI increased by $8.4 \%$, whereas that of SCI did not change significantly. However, given the increase in population density, population aging, and the increased use of motor vehicles, the number of people with SCI is expected to increase. TBI has a higher mortality rate (higher acute injury-related mortality), while TSCI is characterized by a higher standardized mortality rate (shorter long-term life expectancy for SCI survivors; Badhiwala et al., 2019). Public health initiatives to prevent injuries, such as the use of bicycle helmets, fall prevention, policy changes affecting the impact of sports, and other public safety measures, are very effective in reducing the morbidity and mortality associated with TBI and SCI (Taylor et al., 2017). The focus of clinical management involves reducing intracranial pressure, medullary cavity pressure, and cerebral edema, as well as systemic supportive treatment (Maas et al., 2021). In most cases, the effects of these interventions on patients are disappointing (Maas et al., 2017). The burden of disability due to CNS injury can also have a devastating effect on the families of patients because it prevents them from engaging in economic activities. 
TBI is divided into focal tissue damage and diffuse tissue damage. Focal injuries are caused by direct impact and include scalp injuries, skull fractures, brain contusions, cerebral hemorrhage, and stroke, which form focal TBI lesions that can vary greatly in size (Gaetz, 2004). Diffuse injury is caused by acceleration-deceleration forces, including hypoxia-ischemic injury, meningitis, and vascular injury (Gaetz, 2004). However, tissue damage after TBI is rarely purely focal or diffuse, and a single case usually involves multiple focal and diffuse lesions (Skandsen et al., 2010). TBI-related tissue pathology and its functional consequences are heterogeneous and determined largely by: (a) the mechanical properties of the injury; (b) the degree of injury severity (mild, moderate, or severe); and (c) the anatomical location of the injury (Burda et al., 2016). The spinal cord has a unique anatomical structure and the impact of scars on the function of the spinal cord at later stages of SCI can be devastating. Consequently, greater attention is given to pathological changes occurring over time. Several key time points are worth noting, such as the 3rd day after injury when inflammation peaks.

Traumatic injury in the CNS is characterized by transient mechanical damage and subsequent delayed non-mechanical damage (Burda et al., 2016). Primary injury in the brain is caused by mechanical force, which immediately leads to contusion and bleeding in the affected area. In the spinal cord, injury usually relates to vertebral fracture or dislocation (Oyinbo, 2011). The secondary injury occurs hours, days, months, or even years after the initial injury, and is characterized by the expansion of tissue damage from the center of the disease. According to the research in the rodent model of TBI, secondary injury can be simply divided into two parts. The first is inflammation, which peaks on the 3rd day after injury (Susarla et al., 2014). Under the stimulation of a wide variety of pro-inflammatory factors produced as a result of the primary injury, microglia and astrocytes are activated, peripheral immune cells are recruited, and the inflammation cascade is initiated. These effects are accompanied by the destruction of the neurovascular unit, glutamate accumulation, oxidative stress, axonal damage, and neuronal death (Gyoneva and Ransohoff, 2015). The second part involves scar formation, in which glial scars begin to form on day 7 post-injury (Villapol et al., 2014). The glial scar surrounds the site of injury and limits the spread of a strong inflammatory response (Burda and Sofroniew, 2014); however, glial scars secrete a variety of cytokines and proteoglycans that promote neurotoxicity and inhibit axon regeneration, respectively (Silver and Miller, 2004). The outcome of glial scarring is the development of a fibrotic scar, which creates a physical and chemical barrier to axon regeneration and nerve function recovery after injury (O'Shea et al., 2017).

The role of an astrocyte is determined by its subgroup status and the surrounding environment. This diversity of astrocyte function directly affects the inflammatory response and glial scar formation after injury. After an injury, astrocytes interact with surrounding cells, such as neurons, microglia, and endothelial cells, that together constitute the post-injury microenvironment, which plays a pivotal role in disease development (Abbott et al., 2006; Valori et al., 2019).
Although primary CNS injuries cannot be treated, secondary injuries provide a therapeutic window for the treatment of the resulting diseases (Wang et al., 2014). Accordingly, to identify effective treatment strategies, research attention has increasingly focused on the role of astrocytes in the pathology of CNS damage.

\section{ASTROCYTE ACTIVATION AFTER INJURY}

In response to CNS damage, naïve astrocytes are activated and transform into RAs. This transformation involves changes in morphology, increased expression of the intermediate filament proteins GFAP and vimentin, as well as increased proliferation and secretion of inflammatory mediators and growth factors (Karve et al., 2016). After TBI in mouse, astrocytes react within $24 \mathrm{~h}$ and reach a peak of approximately 3-7 dpi, showing a continuous reactive state (Susarla et al., 2014). A recent study conducted using a mouse CCI (chronic constriction injury) model reported the occurrence of astrocyte hypertrophy in the lesion site and surrounding area at 3 days post-injury (dpi). At $7 \mathrm{dpi}$, the morphological changes became long-lasting, and glial scars began to form (Villapol et al., 2014). In this model, reactive gliosis persisted for up to $60 \mathrm{dpi}$, indicative of a continuous response of astrocytes to brain injury (Villapol et al., 2014). In another study, after sensorimotor cortex aspiration in adult rats, astrocyte activation lasted for 16 weeks (Basiri and Doucette, 2010).

\section{Primary Mechanical Stress}

In traumatic CNS injury, mechanical stress can cause neuronal membrane instability and cytoskeleton disintegration (LaPlaca et al., 2009). Astrocytes are activated through plasma membrane stretching. The results of a study using astrocytes cultured on deformable membranes indicated that mechanical strain led to AKT activation in astrocytes via the stimulation of $\mathrm{P} 2$ receptors and promoted ATP release; this, in turn, activated extracellular signal-regulated protein kinase (ERK; Neary et al., 2005). Additionally, the knockout of the Cav1.2 subunit of L-type voltage-operated calcium channels attenuated the migratory and proliferative abilities of astrocytes, indicating that these channels contribute to astrocyte activation, at least in vitro (Cheli et al., 2016). In a mouse model of nerve demyelination, reducing voltage-gated $\mathrm{Ca} 2+$ influx in astrocytes during brain demyelination significantly attenuated brain inflammation and astrocyte reactivity (Zamora et al., 2020). Indeed, calcium is required for ERK activation in astrocytes, and inhibiting these $\mathrm{Ca} 2+$ channels may be an effective means of preventing astrocyte activation and proliferation. In recent research, Hlavac et al showed rat primary astrocytes exposed to high-rate overpressure were mechanically activated, involving changes in structure and junctional proteins (Hlavac and VandeVord, 2019). Their further study indicated that both extracellular adhesion (via FAK activation) and cationic conductance (via ion channels) contribute to this progress (Hlavac et al., 2020). Wakida et al. (2020) showed astrocyte phagocytosis was a mechanosensitive response, and astrocytes exposed to fluid shear stress initiated phagocytosis at a faster rate than cells observed under static 
conditions. Liu J. et al. (2021) proposed Piezo1(mechanosensing channel) in astrocytes was involved in the mechanical activation of astrocytes caused by mechanical stretching.

\section{Secondary Pathological Process}

During the secondary pathological process, the release of intracellular components by the cells injured by primary mechanical stress; activation of microglia and astrocytes at the injured site; production of cytokines and chemokines; and recruitment of peripheral immune cells into CNS, these processes influence each other and produce complex interaction. Peripheral cells released signal factors to recruit extra cells from the periphery and maintain the activation of microglia and astrocytes, leading to excessive activation of astrocytes, which further damaged surrounding tissues and neurons (Gyoneva and Ransohoff, 2015). Additionally, secondary inflammation after CNS injury is the body's reactive inflammation to the injury, which is different from primary neuroinflammation, such as $\mathrm{AD}$, which is caused by the disorder of normal growth and metabolism in cells (Cao et al., 2021).

In the context of post-injury inflammation, the combination of DAMP (HMGB1, Hsp72, HA, ATP) and TLRs drove the complex inflammation network and astrocyte effector events (Struve et al., 2005; Sun et al., 2017; Sun L. et al., 2019; Du et al., 2021; Li et al., 2021b; Michinaga and Koyama, 2021). Cytokines IL- $1 \beta$, IL- 6 , TNF- $\alpha$ activated astrocytes by activating the corresponding receptors and downstream signaling pathways (NFкB, MAPK, NO synthase), and led to the secretion of inflammatory substances (HMGB1, NO, ROS) which further promoted the activation cascade of astrocytes (Swanson et al., 2004; Sun et al., 2017; Sun L. et al., 2019; Patil et al., 2021; Qian et al., 2021). Human spinal cord astrocytes induced by IL$1 \beta$ showed up-regulation of chemokines and axon permissive factors (including FGF2, BDNF, and NGF) expression, and down-regulation of most genes that regulate axon suppression molecules, including ROBO1 and ROBO2 (Teh et al., 2017). After the injury, the EGFR of astrocytes is up-regulated, and mTOR pathway is up-regulated after combining with EGF. The use of EGFR inhibitors effectively reduced reactive astrogliosis (Codeluppi et al., 2009; Li Z. W. et al., 2014). You et al. (2017) proposed that IL-17-JAK/STAT-VEGF axis was involved in the activation of astrocytes after SCI. As a clear target of MIF, the CD74 receptor on the astrocyte membrane binded to MIF, leading to excessive activation of astrocytes, and this process was significantly blocked by c-Jun N-terminal kinase inhibitors (Zhou et al., 2018). But in gecko astrocytes, the combination of MIF and CD74 could not cause obvious inflammation. Du et al. (2021) proved that Vav1 was the key mediator of this phenomenon. In addition, lncRNAPVT1/miR-186-5p/CXCL13/CXCR5 axis and lncRNA H19/miR-1-3p/CCL2 axis were involved in the activation of astrocytes after SCI (Li P. et al., 2020; Zhang P. et al., 2021). MiR-21 regulated the proliferation, secretion, and activation of astrocytes through the PI3K/Akt/mTOR signaling pathway mediated by PTEN, as a positive factor for the recovery of acute SCI (Liu et al., 2018). MiR-17-5p may specifically regulate the proliferation of RAs triggered by LIF through the
JAK/STAT3 pathway (Hong et al., 2014). miR-379 (A et al., 2019), miR-124 (Jiang et al., 2020), miR-145 (Wang et al., 2015), and miR-140 (Tu et al., 2017) negatively regulated astrocyte activation and improved the prognosis of the disease. The transcription factors OLIG2 and SP1, as well as FGF, FGFR, and PDGFR $\beta$ have all been implicated in glial scar formation (Kang et al., 2014; Koyama, 2014; Pei et al., 2017; Table 1). These experimental results obtained in ideal places under different conditions emphasized the heterogeneity of reactive astrocytes at the morphological, functional, biochemical, metabolic, and transcriptome levels. In the complex environment inside the body, they will be covered up.

\section{REACTIVE ASTROCYTES}

RAs are astrocytes that undergo molecular, morphological, and functional changes in response to pathological stimuli from surrounding tissue, such as CNS disease, injury, and deleterious experimental manipulation, among others. As mentioned before, the lifelong adaptive plasticity of astrocytes and the complexity of the disease background determine the diversity of astrocyte subpopulations after injury. In animal models of TBI, P2Y (1)R stimulation was shown to reduce the severity of brain edema and cytotoxic swelling (Talley Watts et al., 2013). However, the results of another study suggested that microglia could convert astrocytes into neurons by mediating the downregulation of P2Y (1)R (Shinozaki et al., 2017). Early et al. (2020) proposed that astrocytes exhibited age-related progressive reactive astrocyte response by the models of TBI in mice of different ages. Recently, Hasel et al. (2021) successfully demonstrated the heterogeneity of RAs in the brain of LPS-induced mouse models. They used single-cell sequencing combined with spatial transcriptomics and in situ hybridization techniques to show that RAs were transcriptome and spatially heterogeneous under inflammatory conditions; and clarified the highly expressed genes and possible functions of RA subtypes in different anatomical locations (Hasel et al., 2021). Combined, the findings of all these studies have highlighted the high heterogeneity of RAs, which can lead to both neuroprotective and toxic effects after CNS injury (Miller, 2018). Differences in in vitro induction conditions; species used in animal models; injury type, degree, and location; and time passed after the injury have all contributed to the contrasting results obtained in different studies. All these make the precise typing of RAs more difficult.

\section{Debris Clearance}

The timely removal of dead cells after CNS injury helps limit secondary tissue damage. Phagocytosis is normally carried out by professional phagocytes. However, several electron microscopybased studies as early as the 1970s showed that astrocytes could swallow small fragments, such as axons or myelin fragments (Ronnevi, 1978). Later, it was discovered that astrocytes were involved in the removal of myelin debris during Wallerian degeneration in the goldfish visual system (Colavincenzo and Levine, 2000). Subsequent studies showed that after CNS injury, astrocytes participate in the removal of axons and myelin fragments, even entire dead cells, thereby protecting injured 
TABLE 1 | Molecules and signaling pathways that involved in the activation of astrocytes.

\begin{tabular}{|c|c|}
\hline Etiology category & Activation factor \\
\hline Primary mechanical force & $\begin{array}{l}\text { Plasma membrane stretching (Neary et al., 2003, 2005), Cav1.2 voltage-gated } \mathrm{Ca}^{2+} \text { channels (Cheli et al., 2016; } \\
\text { Zamora et al., 2020), high-rate overpressure (Hlavac and VandeVord, 2019; Hlavac et al., 2020), fluid shear stress } \\
\text { (Wakida et al., 2020). }\end{array}$ \\
\hline $\begin{array}{l}\text { Cytokines and growth } \\
\text { factors }\end{array}$ & $\begin{array}{l}\text { IL-1 (Teh et al., 2017), IL-6 (Patil et al., 2021), IFN- } \gamma \text {, CNTF, EGF (Li Z. W. et al., 2014), IL-17 (You et al., 2017), TNF- } \alpha \\
\text { (Gayen et al., 2020; Patil et al., 2021), LIF (Kerr and Patterson, 2004; Goodus et al., 2016), VEGF (Gao et al., 2015), MIF } \\
\text { (Du et al., 2021), FGF (Kang et al., 2014), CTGF (Lu M. et al., 2019). }\end{array}$ \\
\hline Chemokines & MCP-1 (Gwak et al., 2012; Joy et al., 2019; Liraz-Zaltsman et al., 2021). \\
\hline Signal transducers & $\begin{array}{l}\text { STAT3, NF-кB, JAK2 (Oliva et al., 2012; You et al., 2017; Li X. et al., 2020), mTOR (Codeluppi et al., 2009), Notch1 } \\
\text { (Ribeiro et al., 2021), MAPK (Zhang X. et al., 2021), ERK (Sticozzi et al., 2013; Li et al., 2021a), PKC (Chao et al., 2018), } \\
\text { SOX9 (Liu W. et al., 2021). }\end{array}$ \\
\hline Receptors & $\begin{array}{l}\text { p75NTR (Chen et al., 2020), CB2R (Jing et al., 2020), ET BR (Koyama, 2021), EGFR (Li Z. W. et al., 2014), TLRs (Kigerl } \\
\text { et al., 2014; Rosciszewski et al., 2018), purine receptor (Li et al., 2021b), FGFR (Kang et al., 2014), PDGFR (Pei et al., } \\
\text { 2017), CD36 (Bao et al., 2012), CD44 (Bourguignon et al., 2007), CD74 (Su et al., 2017). }\end{array}$ \\
\hline Chaperone proteins & Sig-1R, Hsp72, PDIs (Michinaga and Koyama, 2021). \\
\hline Hormones & Neuron-derived estrogen (Lu Y. et al., 2020), noradrenalin (Smith et al., 2005; Bekar et al., 2008). \\
\hline Oxidative stress molecules & NO (Swanson et al., 2004), ROS (Qian et al., 2021). \\
\hline Non-coding RNA & $\begin{array}{l}\text { IncRNAPVT1/miR-186-5p (Zhang P. et al., 2021), IncRNA H19/miR-1-3p (Li P. et al., 2020), miR-21 (Liu et al., 2018), } \\
\text { miR-145 (Wang et al., 2015), miR-140 (Tu et al., 2017), miR-17 (Hong et al., 2014), miR-379 (A et al., } 2019 \text { ), miR-124 } \\
\text { (Jiang et al., 2020). }\end{array}$ \\
\hline Transcription factor & Olig2, Sp1 (Koyama, 2014). \\
\hline Protease & uPA (Diaz et al., 2021), USP18 (Liu W. et al., 2021). \\
\hline Proteins & HMGB1 (Sun et al., 2017; Sun L. et al., 2019), ICAM-1 (Gwak et al., 2012), Galectin-3 (Ribeiro et al., 2021). \\
\hline Peptides & ET-1 (Goodwin and Grizzle, 1994; Michinaga et al., 2018, 2020a). \\
\hline Others & $\begin{array}{l}\text { HA (Struve et al., 2005), Glutamate (Gwak et al., 2012), ATP, Ca }{ }^{2+} \text { (Li et al., 2021b), NG } 2 \text { (Huang et al., 2016), Cr (Ma } \\
\text { et al., 2017). }\end{array}$ \\
\hline
\end{tabular}

neurons from contact-induced cell death (Basiri and Doucette, 2010; Lööv et al., 2012). Morizawa et al. (2017) reported that following brain ischemia, RAs could become phagocytic in a limited spatiotemporal pattern and engulf debris via upregulating the phagocytosis-related ABCA1 pathway. Wang et al. showed that astrocytes directly cleared myelin debris through endocytosis after SCI (Wang S. et al., 2020).

\section{Glutamate Excitotoxicity}

A sharp increase in extracellular glutamate levels has been detected in both CNS injury models and human patients, and this increase represents the cumulative effect of several pathological events that lead to the overstimulation of glutamate receptors and the occurrence of large cation fluxes (Lima et al., 2021). Glutamate excitotoxicity plays an important role in the development of secondary CNS injury. It can lead to neuronal death, followed by prolonged depolarization and subsequent ion imbalance, ATP depletion, increased intracellular free calcium levels, and, ultimately, more serious tissue damage (Jamjoom et al., 2021).

The glutamate transporters GLAST and GLT-1 are mainly expressed in astrocytes and are downregulated following TBI, which leads to enhanced excitotoxicity (Beitchman et al., 2020). Astrocytic excitatory amino acid transporters (EAATs) can protect against neuronal death induced by microgliaderived glutamate, whereas microglial EAATs exert neither neurotoxic nor neuroprotective effects (Liang et al., 2008). These observations indicate that astrocytic glutamate transporters are key for limiting the development of excitotoxic conditions by reducing the concentration of interstitial glutamate. In vitro, oxygen-glucose deprivation/reoxygenation insult can reportedly activate the HMGB1/TLR4 axis and reduce glutamate clearance by inhibiting GLAST expression in primary astrocytes (Lin et al., 2020). Similarly, the downregulation of GLT-1 expression in RAs leads to worse functional and histological outcomes following SCI (Lepore et al., 2011a,b). In addition, during cerebral hemorrhage, astrocytic volume-regulated anion channels release glutamate, further aggravating the damage (Yang J. et al., 2019). Interestingly, $\mathrm{Li}$ et al. illustrated that the overexpression of the astrocytic glutamate transporter GLT1 exacerbated phrenic motor neuron degeneration, diaphragm impairment, and forelimb motor dysfunction post cervical contusion SCI, while the transplantation of glial progenitors that overexpress the glutamate transporter GLT1 could overcome the diaphragm dysfunction (Li K. et al., 2014; Li et al., 2015).

\section{Cytotoxic Edema}

After CNS injury, the brain and spinal cord tissues undergo edema, leading to intracranial or medullary cavity hypertension, secondary to more serious tissue damage that may lead to fatal brain injury or hernia (Liang et al., 2007). Many studies have shown that the degree of cerebral and spinal cord edema is associated with the severity of trauma and subsequent motor dysfunctions (Miyanji et al., 2007). Cytotoxic edema is characterized by the swelling of all cell types due to excessive water retention. In contrast, astrocytes are the main cause of 
brain swelling in brain edema (Liang et al., 2007). AQP-4, expressed in the brain (perivascular and subpial membrane domain) and spinal cord astrocytes, is the most abundant aquaporin in the CNS and represents a major pathway for the entry of excess water into damaged tissue (Nesic et al., 2006; Tait et al., 2008; Saadoun and Papadopoulos, 2010). Astrocytic AQP-4 is primarily responsible for cytotoxic edema after CNS injury (Amiry-Moghaddam et al., 2003).

In animal models of CNS injury, AQP-4 mRNA and protein expression levels are significantly upregulated in activated astrocytes (Finnie et al., 2011; Hemley et al., 2013). Various mechanisms are involved in this process in astrocytes, such as

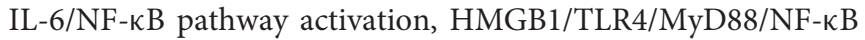
signaling pathway activation, FOXO3A nuclear translocation, and ERK1/2 phosphorylation (Ito et al., 2006; Kapoor et al., 2013; Sun et al., 2017; Sun L. et al., 2019; Zhang et al., 2019a; Li et al., 2021a). Experiments conducted using AQP-4-deficient mice showed that AQP-4 promotes the formation of cytotoxic edema, whereas the absence of AQP-4 reduces edema severity after acute water intoxication, ischemic stroke, and SCI (Manley et al., 2000; Saadoun et al., 2008). In the rat model of TBI, AQP-4 knockdown reportedly reduces the extent of cytotoxic and post-traumatic brain edema (Lu H. et al., 2020). Kitchen et al. suggested that brain or spinal cord swelling was not only related to the total expression of AQP-4, but also the subcellular translocation of AQP-4 to the BSCB. Their data showed that calmodulin could directly bind to the carboxyl terminus of AQP-4, resulting in specific conformational changes and AQP-4 cell-surface localization. In rat SCI models, trifluoperazinemediated calmodulin inhibition suppressed AQP-4 localization to the $\mathrm{BSCB}$, led to the ablation of CNS edema, and resulted in accelerated functional recovery relative to that seen in untreated animals (Kitchen et al., 2020). As shown in Figure 2. As AQP-4 cell surface localization is controlled by calcium/protein kinase $\mathrm{A} /$ calmodulin in astrocytes, targeting calmodulin may also represent a novel treatment method for cytotoxic edema (Kitchen et al., 2015, 2020). In addition to AQP-4, other functional molecules in astrocytes, such as NKCC1, Sur1/Trpm4, AQP-1, and vasopressin are also considered to be initiators of cytotoxic edema formation (Nesic et al., 2008; Jayakumar et al., 2011; Jia et al., 2016; Gerzanich et al., 2019).

\section{BBB/BSCB: Disruption or Recovery}

CNS damage can lead to the loss of $\mathrm{BBB} / \mathrm{BSCB}$ integrity. Astrocytes regulate $\mathrm{BBB} / \mathrm{BSCB}$ homeostasis through end-feet processes that surround endothelial cells. A series of factors derived from RAs after an injury have opposing effects on the BBB/BSCB (Michinaga and Koyama, 2019; Table 2).

Nitric oxide (NO) and excess glutamate derived from RAs after an injury can damage the BBB and the BSCB (Saha and Pahan, 2006; András et al., 2007; Lu L. et al., 2019; Sharma et al., 2019). In animal models of TBI and SCI, the expression of VEGF and MMP-9, both factors that promote $\mathrm{BBB}$ permeability, increases in RAs, and inhibiting them reduces $\mathrm{BBB} / \mathrm{BSCB}$-related damage after injury (Noble et al., 2002; Gao et al., 2015; You et al., 2017; Michinaga et al., 2018; Liu et al., 2020). Astrocyte-derived ET-1 was shown to induce the upregulation of ICAM-1 and VCAM-1 expression in human brain microvascular endothelial cells and aggravate the destruction of the BBB. ET receptor antagonists such as bosentan, BQ788, and S-0139 can alleviate the loss of BBB integrity in TBI model mice (McCarron et al., 1993; Matsuo et al., 2001; Michinaga et al., 2018, 2020a). Interestingly, studies on mice have highlighted that the APOE E4 variant (APOE4) is a risk factor for poor outcomes in CCI. However, APOE is an important modulator of spontaneous BBB stabilization following TBI (Main et al., 2018; Montagne et al., 2020). Astrocyte-derived neurotrophic factor (MANF) can inhibit inflammation and promote angiogenesis and BBB repair (Li et al., 2018). Astrocyte ablation results in the failure of BSCB repair, local tissue destruction, severe demyelination, and the death of neurons and oligodendrocytes following SCI (Faulkner et al., 2004). After CNS injury, the expression of Shh is increased in astrocytes. The administration of exogenous Shh attenuates BBB destruction, while the application of the Shh inhibitor jervine exerts the opposite effects in mice with TBI (Xing et al., 2020; Michinaga et al., 2021). In the mouse SCI model, Shh/Gli1 signaling is induced in RAs and plays an important role in the permeability of BSCB and locomotor recovery after SCI (Yue et al., 2020). The expression of ANG-1 in astrocytes is decreased after CNS injury, while the administration of recombinant ANG-1 can alleviate the destruction of the BBB/BSCB (Sabirzhanov et al., 2019; Michinaga et al., 2020b). Astrocyte-derived FABP7 enhances $\mathrm{BBB}$ integrity through the caveolin-1/MMP signaling pathway after TBI, and displays neuroprotective properties after SCI (Rui et al., 2019; Senbokuya et al., 2019). In addition, astrocytederived retinoic acid and IGF-1 have also been shown to participate in $\mathrm{BBB} / \mathrm{BSCB}$ maintenance and vascular protection (Kong et al., 2015; Bake et al., 2016; Zhou et al., 2016; Li H. et al., 2020). Notably, Shh and MMP-9 can restore or disrupt the $\mathrm{BBB}$ or BSCB through multiple mechanisms, and both proteins have the potential to serve as therapeutic targets for CNS injury.

\section{Inflammation: Basic Protective Function and the Consequences of Overactivation}

Inflammation represents a physiological protective response to injury; however, extreme inflammation, which is inevitable following CNS injury, results in additional tissue damage (Popovich and Jones, 2003; Förstner et al., 2018). RAs promote inflammation after CNS injury by secreting cytokines, chemokines, reactive oxygen species (ROS), NO, and damageassociated molecular patterns, all factors that are involved in the activation of microglia and the recruitment of peripheral immune cells, thereby maintaining and even further aggravating neuroinflammation (Wicher et al., 2017; Linnerbauer et al., 2020). The NF-kB signaling pathway in RAs is a key regulator of inflammation in the CNS (O’Neill and Kaltschmidt, 1997). In animal models of CNS injury, NF- $\kappa \mathrm{B}$ is highly activated and the expression of NF-kB-dependent genes is upregulated (Schneider et al., 1999). Inhibiting NF- $\kappa \mathrm{B}$ signaling dampens astrocyte responses to brain injury, resulting in neuroprotective effects (Acarin et al., 2001; Brambilla et al., 2005). An in vitro study showed that ATP-stimulated human astrocytes 


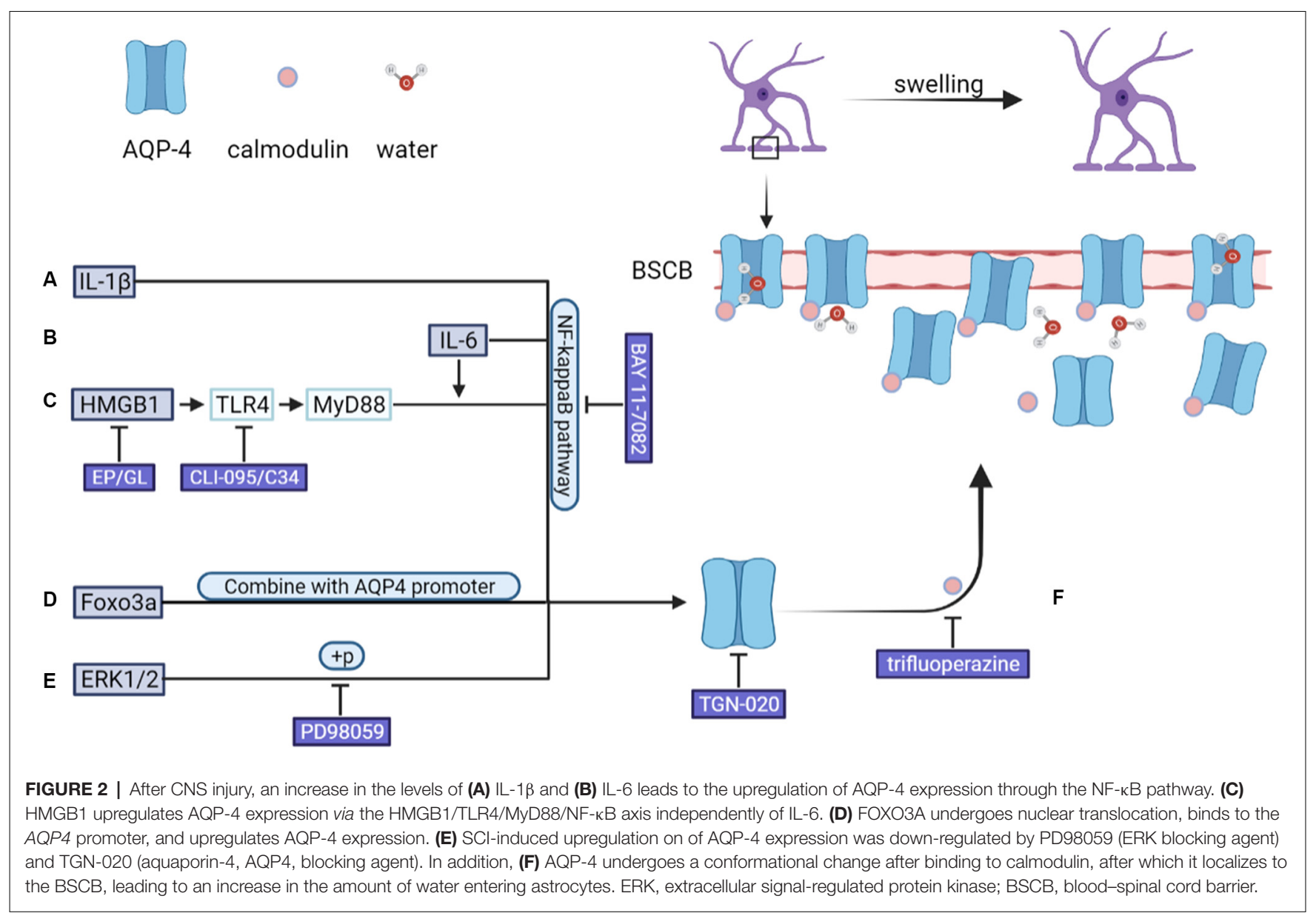

TABLE 2 | Factors destroy or recover BBB/BSCB.

\section{$\mathrm{BBB} / \mathrm{BSCB}$ destruction}

NO (Sharma et al., 2005, 2019; Saha and Pahan, 2006; Buskila et al., 2007; Gu et al., 2012; Jiang et al., 2014)

Excess glutamate (András et al., 2007; Liu et al., 2010; Sulejczak et al., 2016; Lu L. et al., 2019)

VEGF (Gao et al., 2015; You et al., 2017)

MMP-9 (Noble et al., 2002; Michinaga et al., 2018; Liu et al., 2020)

ET-1 (Michinaga et al., 2018, 2020a, 2021)

APOE4 variant (Main et al., 2018; Montagne et al., 2020)

\section{BBB/BSCB recovery}

MANF (Li et al., 2018)

Shh (Xia et al., 2013; Xing et al., 2020; Yue et al., 2020; Michinaga et al., 2021)

Ang-1 (Xia et al., 2013; Sabirzhanov et al., 2019; Sun J. D. et al., 2019; Michinaga et al., 2020b)

fatty acid-binding protein 7 (Rui et al., 2019)

RA (Mizee et al., 2014; Kong et al., 2015; Zhou et al., 2016)

IGF-1 (Bake et al., 2016, 2019; Pitt et al., 2017; Li H. et al., 2020)

APOE4 (Main et al., 2018) activated NLRP2 inflammasomes, while the knockdown of NLRP2 significantly reduced the inflammatory response in human astrocytes (Minkiewicz et al., 2013). Many other pro-inflammatory molecules have been associated with astrocyte reactivity, such asS100 $\beta$, ICAM-1, PrPc, TrkB, D-dopachrome tautomerase, and MIF (Kabadi et al., 2015; Zhang et al., 2019b; Charkviani et al., 2020; Ji et al., 2021; Sulimai et al., 2021). However, using a mouse model of TBI, Myer et al showed that RA ablation aggravated cortical degeneration after moderate CCI, but did not affect cortical degeneration following severe CCI, which suggested that RAs also have a basic protective role in inflammation after injury (Myer et al., 2006). Similar results were obtained with astrocyte ablation after SCI (Faulkner et al., 2004). Long et al. (2020) showed that astrocyte-derived exosomes enriched with miR-873a-5p can inhibit the NF- $\mathrm{B}$ signaling pathway and promote the transformation of protective M2 microglia, thereby inhibiting excessive neuroinflammation. Additionally, Zaheer et al. (2001) showed that activation of the NF- $\mathrm{B}$ signaling pathway resulted in the synthesis of neurotrophic factors (nerve growth factor and brain-derived neurotrophic factor), which is essential for neuronal survival after injury. 


\section{RA SUBGROUP WITH NEUROTOXICITY}

As early as 2012, Zamanian et al. (2012) discovered a potentially harmful subgroup of RAs. Subsequently, Liddelow et al. (2017) proposed a neurotoxic RA with $\mathrm{C} 3$ as a molecular marker and named it A1 astrocytes. A1 astrocytes were induced by cytokines (TNF- $\alpha$, IL- $1 \alpha$, and complement component C1q) secreted by activated microglia. Although the concept of A1 is not relevant in this field, many previous research results of A1 neurotoxic astrocytes can help subsequent research on the neurotoxic subpopulations of RAs. A1 astrocytes lose many basic functions and gain harmful ones when compared with normal astrocytes. Namely, A1 astrocytes have fewer synapses and a weaker ability for synapse induction; impaired myelin scavenging ability; they can inhibit oligodendrocyte maturation; exhibit stronger neurotoxicity; and kill CNS neurons that have severed axons (Liddelow et al., 2017; Li X. et al., 2020). A1 astrocytes have a significantly different morphology: long dendrites (Zou et al., 2019). This suggests that the morphology of RAs may be changeable. Adding morphological features to the subgroup division can make the typing more specific and accurate. A1 astrocytes are found in a variety of CNS injuries and neurodegenerative diseases but are also present during the normal aging process (Clarke et al., 2018; Yun et al., 2018; Zheng et al., 2021). Alawieh et al. showed that a significant increase in C3 levels after CNS injury triggers continuous microglia degeneration and astrocyte activation, reduces dendrite and synapse density, and ultimately leads to the loss of neurons (Alawieh et al., 2018; Clark et al., 2019). After SCI, mice with C3 deficiency have reduced inflammation and secondary damage and better nerve regeneration and functional recovery after injury compared with that for normal mice (Guo et al., 2010). However, mice with C3aR deficiency show abnormal neurodevelopment that persists into adulthood, and is characterized by locomotive hyperactivity and altered cognitive functions (Pozo-Rodrigálvarez et al., 2021). Wang et al. (2021) proposed a more radical possibility, namely, that A1 astrocytes could directly kill neurons by secreting neurotoxic C3. Several studies have reported that $\mathrm{C} 3$ is closely related to the onset of multiple neurodegenerative diseases (Lian et al., 2015; Litvinchuk et al., 2018). These observations suggest that the basic C3 level is necessary for the maintenance of a normal physiological environment in the CNS, whereas excessive C3 availability produces neurotoxic effects after injury. However, it must be acknowledged that the expression of a singular marker "C3" is not a definitive marker that identifies A1 astrocytes. The work of Boisvert et al. (2018) showed that C3 was upregulated on astrocytes in the condition of aging, and did not necessarily, or categorically, indicate A1 astrocytes. Therefore, it is neither accurate nor objective that $\mathrm{C} 3$ is used as a singular marker of A1 astrocytes in injury and diseases in humans and other models. Recently, Guttenplan et al. (2021) proposed that saturated lipids contained in APOE and APOJ lipid particles mediated the neurotoxicity of RAs. Astrocytes specifically knock out saturated lipid synthase ELOVL1 to eliminate the formation of long-chain saturated lipids, which reduced astrocyte-mediated toxicity.

In CNS injury, a variety of substances and intracellular signal pathways are involved in the induction and transformation of the functions of RAs (neurotoxicity and neuroprotection; Table 3). For instance, the activation of the NF- $\kappa$ B and Notch signal pathways promotes A1 transformation, while exposure to mesenchymal stem cell (MSC)-derived exosomes, which play anti-inflammatory and neuroprotective roles after SCI, suppresses A1 astrocyte numbers by inhibiting the NF- $\mathrm{B}$ signaling pathway (Wang et al., 2018; Liu et al., 2019; Qian et al., 2019). Additionally, activating the FGF2/FGFR1 pathway can reverse the increase in C3 expression levels in astrocytes following ultrasound exposure (Zou et al., 2019). After SCI, the application of electrospun fiber was reported to promote the expression of A1-specific markers, but electrospun fibercontaining TGF elicited the opposite effect (Gottipati et al., 2020). In comparison, in an IL- $1 \beta$-induced neonatal rat model of white matter injury, astrocytes showed A2 reactivity (Shiow et al., 2017). After TBI, neuron-derived prokineticin 2 and astrocyte-derived estrogen activated STAT3 signaling pathway in astrocytes, leading to the upregulation of A2 astrocytes (Neal et al., 2018; Ma et al., 2020; Wang J. et al., 2020).

TABLE 3 | Neurotoxic astrocyte-related substances and signal pathways.

\begin{tabular}{|c|c|c|c|}
\hline Effect & Inductive molecule & Signal path & Reference \\
\hline \multirow[t]{4}{*}{ Reduce neurotoxicity } & MSC-exo & NF-K (-) & Wang et al. (2018) and Liu et al. (2019) \\
\hline & HSF1 & NF-кB (-) MAPKs (-) & Li L. et al. (2021) \\
\hline & - & FGF2/FGFR1 (+) & Zou et al. (2019) \\
\hline & TGF- $\beta 3$ & - & Gottipati et al. (2020) \\
\hline \multirow[t]{2}{*}{ Induce neuroprotection } & $\mathrm{IL}-1 \beta$ & - & Shiow et al. (2017) \\
\hline & PK2 & STAT3 $(+)$ & Neal et al. (2018) and Ma et al. (2020) \\
\hline \multirow[t]{4}{*}{ Reduce neurotoxicity and Induce neuroprotection } & miR-21 & STAT3 (+) & Su et al. (2019) \\
\hline & MFG-E8 & PI3K-Akt (+) \& NF-KB (-) & Xu et al. (2018) \\
\hline & MSC-EVs & - & Kaminski et al. (2020) \\
\hline & Wnt-3a & Wnt/ß-catenin signaling pathway (+) & Zhang D. et al. (2019) \\
\hline
\end{tabular}


We have previously shown that miR-21, a regulator of the STAT3 pathway, can transform neurotoxic (A1) RAs into an A2 phenotype (Su et al., 2019). MFG-E8, MSC-derived extracellular vesicles (EVs), Wnt-3a, and $\operatorname{Trk} \beta$ have also been shown to be involved in A1/A2 transformation (Xu et al., 2018; Zhang D. et al., 2019; Kaminski et al., 2020; Miyamoto et al., 2020). Interestingly, FGF2 can inhibit the TGF- $\beta 1$-induced increase in GFAP expression in astrocytes (Tran et al., 2018). The antagonism between different molecules that induce the same phenotype further underlines the need for the development of a more precise method for typing RAs.

\section{GLIAL SCARS AND SAS}

Following CNS injury, naive astrocytes transform into RAs, and then eventually SAs, leading to impaired axon regeneration and functional recovery. This continuous phenotypic change is a manifestation of astrocyte reactivity, which was once considered to be a unidirectional and irreversible process (Hara et al., 2017). Diseases and injuries of the CNS are usually accompanied by a certain degree of scar formation, although scar formation differs according to disease and injury (Smith et al., 2015). Glial scars are mainly involved in the repair process after CNS injury. After SCI, damage repair efficiency is low and the resulting pathological changes cannot be overcome. Consequently, here, we focus on astrocyte-mediated scar formation after SCI (Bradbury and Burnside, 2019). SCI lesions exhibit three compartments: a non-neural (stromal) lesion core, astrocyte scar borders, and spared but reactive neural tissue. SAs participate in the formation of astrocyte scar borders (Sofroniew, 2018). The scarring process begins on day 7 post-injury and involves the misalignment of activated astrocytes and the deposition of inhibitory CSPGs. SAs can be identified from 14 dpi (Hara et al., 2017).

Various mediators are involved in glial scar formation, including TGF- $\beta 1 / 2$, IFN- $\gamma$, FGF, MMP-9, fibrinogen, and STAT3 (Moon and Fawcett, 2001; Herrmann et al., 2008; Hsu et al., 2008; Schachtrup et al., 2010). The glial scar represents a physical barrier that enwraps damaged tissues and restricts the migration of inflammatory cells from the non-neural lesion core to the CNS parenchyma (Voskuhl et al., 2009; Sofroniew, 2015). Glial scars fill the interstitial spaces and induce the formation of new capillaries (Rolls et al., 2009). RA ablation impairs glial scar formation, leading to extensive infiltration of inflammatory cells and loss of neurons (Gu et al., 2019). Importantly, however, RA ablation also exerts an unwelcome inhibitory effect on axon regeneration (Anderson et al., 2016). CSPGs deposited in glial scars inhibit oligodendrocyte precursor cell differentiation and remyelination, the two most important processes underlying axon regeneration. CSPG inhibition or inactivation effectively improves motor function (Bradbury et al., 2002; Silver and Miller, 2004; Siebert et al., 2011; Lang et al., 2015; Tran et al., 2018). Wallerian degeneration of damaged axon protrusions leads to continuous extracellular deposition of axons and myelin debris. Myelin-related molecules (MAG, Nogo, OMGP), in conjunction with CSPGs, inhibit neuronal regeneration and neural plasticity (Sofroniew, 2018).
However, the deletion of CSPG-related genes or CSPG receptor blockade only enhances synaptic remodeling and cannot directly overcome the protective effects of the astrocyte scar and lesion cores of non-neural tissue to produce meaningful spontaneous axonal regeneration (Hossain-Ibrahim et al., 2007; García-Alías et al., 2009). A combination of TGF- $\beta 1 / 2$ antibodies reduced CNS scar formation in an adult rat model of brain injury; however, this was not accompanied by an increase in axon regeneration (Moon and Fawcett, 2001). GFAP ${ }^{-1-}$ vim $^{-1-}$ mice show normal scar formation after TBI or SCI, but the scar density is low and accompanied by bleeding (Pekny et al., 1999). Three genetically targeted loss-of-function interventions-preventing astrocyte scar formation, attenuating scar-forming astrocytes, and ablating chronic astrocytic scars-all failed to promote spontaneous axon regrowth. However, exogenous administration of axon-specific growth factors, coupled with growth-activating priming injuries, stimulated axon regeneration, which was reversed by glial scar ablation (Anderson et al., 2016).

Glial scars transform into fibrous scars $14 \mathrm{dpi}$, and SAs are produced at the same time. SAs are known to originate from the interaction between RAs and type I collagen via the integrin/N-cadherin pathway. Antibodies targeting collagenbinding integrin and $\mathrm{N}$-cadherin neutralizing antibodies both inhibited this process (Hara et al., 2017). Immunofluorescence analysis identified the presence of SOX9-positive nuclei in astrocytes of a wild-type brain scar 30 days after the cortical puncture. In contrast, SOX9 expression was strictly limited to the cytoplasm in the $\mathrm{DBN}-/-$ brain. $\mathrm{DBN}$ may also participate in the transformation of RAs into SAs (Schiweck et al., 2021). Inhibiting the RA/SA conversion may represent an ideal treatment for CNS injury. For this, the restrictive effect of RAs on inflammation should not be affected, only the formation of the glial scar boundary should be inhibited so as to alleviate the inhibitory effect of the surrounding environment on axon regeneration.

In summary, the dual role of the glial scar in axon regeneration may result from the low inherent regeneration potential of neurons. The growth-activating effect of the glial scar cannot bridge the gap between the neuronal regeneration potential and the physical hindrance represented by glial scars; when a glial scar is ablated, neurons cannot regenerate axons on their own without the growth-activating effect of the glial scar. Han et al. (2020) proposed to increase the intrinsic regenerative power of neurons by restoring cellular energy, and successfully promoted the germination and regeneration of axons after SCI by enhancing mitochondrial transport and energy metabolism. Therefore, in the case of preserving glial scars, enhancing the regeneration potential of neurons may also be a feasible treatment option.

\section{STRATEGIES FOR ASTROCYTE-TARGETED THERAPY}

Based on the dual role of astrocytes in CNS injury, multiple attempts have been undertaken to enhance the beneficial effects of astrocytes or reduce their harmful effects. Here, we 
TABLE 4 | Diverse astrocyte targeted therapy strategies.

\begin{tabular}{|c|c|c|c|c|c|}
\hline Target & Treatment & Model & Mechanism & Curative effect & Reference \\
\hline \multirow[t]{8}{*}{$\begin{array}{l}\text { Inhibit excessive } \\
\text { activation of astrocytes }\end{array}$} & $\mathrm{MP}$ & $\begin{array}{l}\text { In vivo } \\
\text { In vitro }\end{array}$ & $\begin{array}{l}\text { Down-regulate astrocyte } \\
\text { activation and inhibit CSPG } \\
\text { expression }\end{array}$ & $\begin{array}{l}\text { Improve neuron repair and } \\
\text { promote neurite outgrowth } \\
\text { after excitotoxic injury }\end{array}$ & Liu et al. (2008) \\
\hline & Melatonin & In vivo & Inhibit astrocyte activation & Reduce neuronal apoptosis & Babaee et al. (2015) \\
\hline & PPR & In vivo & $\begin{array}{l}\text { Down-regulate TNF- } \alpha \text {, } \\
\text { IL- } 1 \beta \text {, reduce GFAP+ } \\
\text { astrocyte cells }\end{array}$ & $\begin{array}{l}\text { Reduce the degree of } \\
\text { cerebral edema and } \\
\text { seizures }\end{array}$ & Song Y. et al. (2020) \\
\hline & $\mathrm{TBHQ}$ & In vivo & $\begin{array}{l}\text { Reduce the production of } \\
\text { M1 microglia and } \\
\text { inflammatory cytokines, } \\
\text { significantly reduce the } \\
\text { excessive activation of } \\
\text { astrocytes }\end{array}$ & $\begin{array}{l}\text { Reduce neuronal death and } \\
\text { lesion volume, improve } \\
\text { motor function and } \\
\text { cognitive deficits }\end{array}$ & Zhang et al. (2020) \\
\hline & AS-IV & In vitro & $\begin{array}{l}\text { AS-IV reduces the } \\
\text { activation of the } \\
\text { CXCR4/JNK pathway and } \\
\text { ultimately up-regulates the } \\
\text { Keap1-Nrf2 signaling }\end{array}$ & $\begin{array}{l}\text { Prevent OGD/R-induced } \\
\text { astrocyte apoptosis }\end{array}$ & Yang J. et al. (2021) \\
\hline & Simvastatin & $\begin{array}{l}\text { In vivo } \\
\text { In vitro }\end{array}$ & $\begin{array}{l}\text { Simvastatin manipulates } \\
\text { the caveolin-1 expression in } \\
\text { lipid rafts in the astrocyte } \\
\text { cell membrane, reduces } \\
\text { EGFR phosphorylation, and } \\
\text { finally reduces IL-1 } \\
\text { production and astrocyte } \\
\text { activation }\end{array}$ & Protect neurons & $\begin{array}{l}\text { Li et al. (2009) and Wu } \\
\text { et al. (2010) }\end{array}$ \\
\hline & ONO-2506 & In vivo & $\begin{array}{l}\text { Inhibit the production of } \\
\text { S100B by astrocytes to } \\
\text { inhibit the activation of } \\
\text { astrocytes }\end{array}$ & $\begin{array}{l}\text { Reduce neuropathic pain } \\
\text { after } \mathrm{SCl}\end{array}$ & Ishiguro et al. (2019) \\
\hline & Edaravone & In vivo & $\begin{array}{l}\text { Reduce astrocyte } \\
\text { proliferation in a rat model } \\
\text { of propofol-induced brain } \\
\text { injury through the } \\
\text { BDNF/TrkB pathway. }\end{array}$ & Reduce inflammation & Yang Y. et al. (2021) \\
\hline \multirow[t]{7}{*}{ Reduce Edema } & $\begin{array}{l}\text { Functionalized } \\
\text { Phenylbenzamides }\end{array}$ & $\begin{array}{l}\text { In vivo } \\
\text { In vitro }\end{array}$ & $\begin{array}{l}\text { Reduce AQP-4-mediated } \\
\text { water Permeability }\end{array}$ & $\begin{array}{l}\text { Reduce brain edema and } \\
\text { improve prognosis }\end{array}$ & Farr et al. (2019) \\
\hline & TGN-020 & In vivo & $\begin{array}{l}\text { Inhibit the expression of } \\
\text { AQP-4, GFAP, PCNA }\end{array}$ & $\begin{array}{l}\text { Reduce spinal cord edema } \\
\text { and promote axon } \\
\text { regeneration }\end{array}$ & Li et al. (2019) \\
\hline & Atorvastatin & In vivo & $\begin{array}{l}\text { Inhibit } \\
\text { p38MAPK-dependent } \\
\text { pathway to down-regulate } \\
\text { the expression of AQP4 }\end{array}$ & $\begin{array}{l}\text { Reduce ischemic brain } \\
\text { edema }\end{array}$ & Cheng et al. (2018) \\
\hline & Goreisan & In vivo & $\begin{array}{l}\text { Decrease AQP-4expression } \\
\text { level }\end{array}$ & $\begin{array}{l}\text { Reduce brain water } \\
\text { content, alleviate motor } \\
\text { deficits }\end{array}$ & Nakano et al. (2018) \\
\hline & Trifluoperazine & $\begin{array}{l}\text { In vivo } \\
\text { In vitro }\end{array}$ & $\begin{array}{l}\text { Prevent calmodulin from } \\
\text { directly binding to the } \\
\text { carboxyl terminus of } \\
\text { AQP-4, which inhibit AQP-4 } \\
\text { localization BSCB }\end{array}$ & $\begin{array}{l}\text { Relieve CNS edema and } \\
\text { accelerate functional } \\
\text { recovery }\end{array}$ & Kitchen et al. (2020) \\
\hline & Bosentan & $\begin{array}{l}\text { In vivo } \\
\text { In vitro }\end{array}$ & $\begin{array}{l}\text { Decrease the expression } \\
\text { levels of MMP-9, VEGF-A, } \\
\text { and Ang-1 in the brain after } \\
\text { injury }\end{array}$ & $\begin{array}{l}\text { Reduce BBB dysfunction } \\
\text { and cerebral edema }\end{array}$ & Michinaga et al. (2020a) \\
\hline & BQ788 & In vivo & $\begin{array}{l}\text { Reduce GFAP-positive } \\
\text { astrocytes and their } \\
\text { products: VEGF-A and } \\
\text { MMP9 }\end{array}$ & $\begin{array}{l}\text { Promote the recovery of } \\
\text { BBB function and reduce } \\
\text { cerebral edema }\end{array}$ & Michinaga et al. (2018) \\
\hline
\end{tabular}


TABLE 4 | Continued

\begin{tabular}{|c|c|c|c|c|c|}
\hline Target & Treatment & Model & Mechanism & Curative effect & Reference \\
\hline & Ulinastatin & In vivo & $\begin{array}{l}\text { Decrease the activation of } \\
\text { ET-1 and inhibit the } \\
\text { expression of } \\
\text { pro-inflammatory VEGF and } \\
\text { MMP-9 }\end{array}$ & $\begin{array}{l}\text { Reduce brain edema after } \\
\text { TBI }\end{array}$ & Liu T. et al. (2021) \\
\hline & EP/GL & In vivo & $\begin{array}{l}\text { Inhibit the activation of } \\
\text { astrocytes, reduce the } \\
\text { expression of AQP4, and } \\
\text { inhibit the activation of the } \\
\text { TLR4/NF-кB signaling } \\
\text { pathway }\end{array}$ & $\begin{array}{l}\text { Improve motor function and } \\
\text { reduce early spinal cord } \\
\text { edema }\end{array}$ & $\begin{array}{l}\text { Sun et al. (2017) and } \\
\text { Sun L. et al. (2019) }\end{array}$ \\
\hline \multirow[t]{6}{*}{$\begin{array}{l}\text { Astrocyte } \\
\text { reprogramming }\end{array}$} & OCT4, NANOG & In vitro & & $\begin{array}{l}\text { Astrocytes are } \\
\text { reprogrammed into the } \\
\text { generation of cells } \\
\text { expressing neural } \\
\text { stem/precursor markers }\end{array}$ & Corti et al. (2012) \\
\hline & SOX2 & In vivo & & $\begin{array}{l}\text { Resident astrocytes are } \\
\text { reprogrammed into } \\
\text { proliferating neuroblasts }\end{array}$ & Niu et al. (2013) \\
\hline & Zfp521 & $\begin{array}{l}\text { In vivo } \\
\text { In vitro }\end{array}$ & & $\begin{array}{l}\text { Astrocytes are } \\
\text { reprogrammed into iNSCs } \\
\text { or neurons }\end{array}$ & $\begin{array}{l}\text { Su et al. (2014) and } \\
\text { Zarei-Kheirabadi et al. } \\
(2019 a, b)\end{array}$ \\
\hline & $\begin{array}{l}\text { Transcription } \\
\text { factors PAX6, } \\
\text { NGN2 and ASCL1 }\end{array}$ & In vitro & & $\begin{array}{l}\text { Reprogramming of } \\
\text { astrocytes into neurons }\end{array}$ & $\begin{array}{l}\text { Heins et al. (2002) and } \\
\text { Berninger et al. (2007) }\end{array}$ \\
\hline & $\begin{array}{l}\text { Combination of } \\
\text { transcription factors } \\
\text { Brn-2a, MyT1L, } \\
\text { and ASCL1 }\end{array}$ & In vivo & & $\begin{array}{l}\text { Reprogramming of } \\
\text { astrocytes into neurons }\end{array}$ & Torper et al. (2013) \\
\hline & $\begin{array}{l}\text { Transcription } \\
\text { factors NeuroD1 }\end{array}$ & In vivo & & $\begin{array}{l}\text { Reprogramming of } \\
\text { astrocytes into neurons }\end{array}$ & Puls et al. (2020) \\
\hline \multirow[t]{6}{*}{$\begin{array}{l}\text { Reduce the toxicity of } \\
\text { RAs and protect } \\
\text { neurons }\end{array}$} & $\begin{array}{l}\text { Drug-Loaded } \\
\text { Nano-Structured } \\
\text { Gel }\end{array}$ & $\begin{array}{l}\text { In vivo } \\
\text { In vitro }\end{array}$ & $\begin{array}{l}\text { Down-regulate } \\
\text { A1 astrocytes, reduce iNOS } \\
\text { and Lcn2 }\end{array}$ & $\begin{array}{l}\text { Improve early exercise } \\
\text { ability of injury and protect } \\
\text { neurons }\end{array}$ & Vismara et al. (2020) \\
\hline & Ponesimod & $\begin{array}{l}\text { In vivo } \\
\text { In vitro }\end{array}$ & $\begin{array}{l}\text { Reduce A1 astrocyte } \\
\text { polarization by activating } \\
\text { the STAT3 signaling } \\
\text { pathway }\end{array}$ & $\begin{array}{l}\text { Prevent neuronal death } \\
\text { from early brain injury after } \\
\text { subarachnoid hemorrhage }\end{array}$ & Zhang L. et al. (2021) \\
\hline & $\begin{array}{l}\text { Epidermal Growth } \\
\text { Factor Hydrogels }\end{array}$ & In vitro & $\begin{array}{l}\text { Down-regulate negative } \\
\text { A1-like genes (Fbln5 and } \\
\text { Rt1-S3) and up-regulate } \\
\text { potentially beneficial A2-like } \\
\text { genes (Clcf1, Tgm1, and } \\
\text { Ptgs2) }\end{array}$ & $\begin{array}{l}\text { Enhance neuroprotection } \\
\text { and neuroplasticity }\end{array}$ & Chan et al. (2019) \\
\hline & RTMS & $\begin{array}{l}\text { In vivo } \\
\text { In vitro }\end{array}$ & $\begin{array}{l}\text { Reduce the production of } \\
\text { inflammatory mediators, } \\
\text { promote HIF-1 } 1 \alpha \text { signaling, } \\
\text { transform A2 astrocytes } \\
\text { into A1 astrocytes }\end{array}$ & $\begin{array}{l}\text { Reduce neuronal } \\
\text { apoptosis, promote blood } \\
\text { vessel repair, and improve } \\
\text { cognitive function. }\end{array}$ & Zong et al. (2020) \\
\hline & Physical exercise & In vivo & $\begin{array}{l}\text { Down-regulate the } \\
\text { expression of IL- } 1 \alpha, \mathrm{C} 1 \mathrm{q} \text {, } \\
\text { and TNF, up-regulate the } \\
\text { release of TGF } \beta \text {, and } \\
\text { promote the conversion of } \\
\text { A1astrocytes to } \\
\text { A2 astrocytes }\end{array}$ & $\begin{array}{l}\text { Promote white matter repair } \\
\text { and cognitive improvement }\end{array}$ & Jiang et al. (2021) \\
\hline & RvD1 & $\begin{array}{l}\text { In vivo } \\
\text { In vitro }\end{array}$ & $\begin{array}{l}\text { Induces higher levels of } \\
\text { mitochondrial autophagy in } \\
\text { astrocytes to protect the } \\
\text { mitochondrial morphology } \\
\text { and membrane potential of } \\
\text { the astrocytes }\end{array}$ & $\begin{array}{l}\text { Reduce cognitive } \\
\text { impairment and brain } \\
\text { edema, improve the neuron } \\
\text { survival rate after TBI }\end{array}$ & Ren et al. (2020) \\
\hline
\end{tabular}


TABLE 4 | Continued

\begin{tabular}{|c|c|c|c|c|c|}
\hline Target & Treatment & Model & Mechanism & Curative effect & Reference \\
\hline & Baicalin & $\begin{array}{l}\text { In vivo } \\
\text { In vitro }\end{array}$ & $\begin{array}{l}\text { Inactivate SDH to inhibit } \\
\text { ROS production and } \\
\text { reduce the loss of GS } \\
\text { protein in astrocytes after } \\
\text { injury }\end{array}$ & $\begin{array}{l}\text { Reduce excitotoxicity and } \\
\text { protect neurons }\end{array}$ & Song X. et al. (2020) \\
\hline & LEC & In vivo & $\begin{array}{l}\text { Reduce lipid peroxidation of } \\
\text { astrocytes and increase } \\
\text { their glutamate uptake }\end{array}$ & $\begin{array}{l}\text { Reduce excitotoxicity and } \\
\text { protect neurons and } \\
\text { oligodendrocytes }\end{array}$ & Lima et al. (2021) \\
\hline & Ganglioside GM1 & $\begin{array}{l}\text { In vivo } \\
\text { In vitro }\end{array}$ & $\begin{array}{l}\text { GM stimulates the } \\
\text { expression of genes related } \\
\text { to glucose metabolism and } \\
\text { enhances glycolysis in } \\
\text { astrocytes }\end{array}$ & Protect neurons & Finsterwald et al. (2021) \\
\hline Others & Ferrostatin-1 & In vitro & $\begin{array}{l}\text { Suppress the ROS levels } \\
\text { and activate the } \\
\mathrm{Nrf} 2 / \mathrm{HO}-1 \text { signaling } \\
\text { pathway }\end{array}$ & $\begin{array}{l}\text { Alleviate astrocytes } \\
\text { inflammation and } \\
\text { ferroptosis }\end{array}$ & Li S. et al. (2021) \\
\hline
\end{tabular}

mainly review the existing attempts at astrocyte-targeted therapy (Table 4).

\section{Inhibit Excessive Activation of Astrocytes}

In the inflammatory phase after CNS injury, excessive activation of astrocytes aggravates the inflammatory cascade and has a negative impact on the prognosis of the disease (Johnson et al., 2013). Methylprednisolone (MP) is a typical representative of an RA-targeting molecule that has already been used in the clinic. MP can reduce astrocyte activation and downregulate the expression of CSPG, thereby promoting the growth of neurites after injury (Liu et al., 2008). Melatonin can exert similar effects (Babaee et al., 2015). PPR, TBHQ, AS-IV, and simvastatin can all reduce the production of inflammatory mediators and inhibit excessive astrocyte activation, thereby protecting neurons and improving prognosis (Li et al., 2009; Wu et al., 2010; Song Y. et al., 2020; Zhang et al., 2020; Yang J. et al., 2021). ONO-2506 can also attenuate astrocyte activation, thus minimizing secondary damage and relieving neuropathic pain after SCI (Ishiguro et al., 2019). As a variety of free radical scavengers, edaravone alleviated astrocyte proliferation and inflammation in a rat model of propofolinduced brain injury (Yang Y. et al., 2021). The selective inhibitor of D-dopachrome tautomerase, a close homolog of MIF protein, effectively attenuated the inflammatory activation of astrocytes after SCI and improves motor function, which helps to develop the application of anti-inflammatory drugs in CNS injuries (Ji et al., 2021). In fact, anti-inflammatory drugs have been used in the clinical treatment of CNS injuries for a long time.

\section{Reduce Edema}

AQP-4 is the best-characterized astrocyte-related molecule. Functionalized phenylbenzamide, TGN-020, atorvastatin, and goreisan all target AQP-4, improving post-injury edema and prognosis (Cheng et al., 2018; Nakano et al., 2018; Farr et al., 2019; Li et al., 2019). Using a rat model of SCI, Kitchen et al administered trifluoperazine to inhibit the direct binding of calmodulin to the carboxyl terminus of AQP-4, which inhibited its localization to the BSCB. This effect relieved CNS edema and accelerated functional recovery relative to untreated animals (Kitchen et al., 2020; Figure 2). However, in a review by Nesic et al. (2010), the authors proposed that the therapeutic effect of AQP-4 depends not only on the time interval after SCI or the animal model but also on the balance between the protective effect of increased AQP-4 levels on hypoxia and the harmful effects associated with sustained astrocyte swelling. ET-1 has also received widespread attention as a putative therapeutic target. Both bosentan (an $\mathrm{ET}_{\mathrm{A}} / \mathrm{ET}_{\mathrm{B}}$ antagonist) and BQ788 (an $\mathrm{ET}_{\mathrm{B}}$ antagonist) effectively attenuated $\mathrm{BBB}$ disruption and cerebral edema in both patients and mice with TBI, whereas the $\mathrm{ET}_{\mathrm{A}}$ antagonists ambrisentan and FR139317 elicited no effect (Michinaga et al., 2018, 2020a; Liu T. et al., 2021). This suggests that the deleterious effect of ET-I following CNS injury mainly depends on $\mathrm{ET}_{\mathrm{B}} \mathrm{R}$. Additionally, EP/GL inhibited the 
activation of astrocytes, reduced the expression of AQP4 and early spinal cord edema (Sun et al., 2017; Sun L. et al., 2019).

\section{Reduce the Toxicity of RAs and Protect Neurons}

A drug-loaded nano-structured gel and ponesimod were shown to improve motor performance in the early stages after injury and protect neurons by suppressing the activation of the neurotoxic phenotype of RAs (Vismara et al., 2020; Zhang L. et al., 2021). Epidermal growth factor-containing hydrogels can reportedly alter astrocyte behavior, i.e., they downregulate the expression of deleterious neurotoxicity-related genes (Fbln5 and Rt1-S3) while upregulating that of potentially beneficial neuroprotective phenotype-associated genes (Clcf1, Tgm1, and Ptgs2), thereby indirectly enhancing neuroprotection and neuroplasticity (Chan et al., 2019). RTMS, HSF1, and physical exercise also lead to the conversion of the neurotoxic phenotype into the neuroprotective phenotype, which promotes functional recovery after injury (Zong et al., 2020; Jiang et al., 2021; Li L. et al., 2021). Mitochondria may also play a role in A1 polarization. Incubation with cobalt chloride (CoCl2) converted astrocytes from an A2 to an A1 state, concomitant with a reduction in mitochondrial migration. $\operatorname{Trk} \beta$ agonists can convert A1 astrocytes to an A2 phenotype via reducing mitochondria migration (Miyamoto et al., 2020). Mitochondrial transplantation after CNS injury decreases the release of inflammatory factors such as IL- $1 \beta$ and TNF- $\alpha$ and significantly suppresses astrocyte and microglia activation, thus protecting neurons and promoting functional recovery (Zhang Z. et al., 2019). Resolvin D1 protected mitochondrial morphology and membrane potential in astrocytes, removed damaged mitochondria and thereby enhanced the survival of neurons (Ren et al., 2020). This prompts us to pay attention to the impact of the energy status of RAs on their function in the context of disease. A better understanding of the changes occurring in mitochondrial morphology and function after CNS insult may yield novel strategies for the treatment of CNS injuries. Baicalin and LEC were shown to stabilize astrocytes after injury and increase their glutamate uptake, effects that can reduce excitotoxicity and protect both neurons and oligodendrocytes (Song X. et al., 2020; Lima et al., 2021). Agathisflavone and ganglioside GM1 promoted the neuroprotective effect of astrocytes (de Amorim et al., 2020; Finsterwald et al., 2021).

\section{Astrocyte Reprogramming}

Astrocytes retain limited neural stem cell potential and can be reprogrammed into a stem cell-like state to replenish neurons lost after injury (Kriegstein and Alvarez-Buylla, 2009; Verkhratsky and Nedergaard, 2018). The transcription factors OCT4, SOX2, NANOG, and zinc-finger nuclear protein Zfp521 can individually reprogram mature astrocytes into neural stem cells (Corti et al., 2012; Niu et al., 2013; Su et al., 2014; Yang H. et al., 2019; Zarei-Kheirabadi et al., 2019b). The transcription factors PAX6, NGN2, and ASCL1, participate in the transformation of astrocytes into neurons in vitro (Heins et al., 2002; Berninger et al., 2007), similar to that seen with the combination of three nerve conversion factors (ASCL1, Brn-2a, and MyT1L) in vivo (Torper et al., 2013). Noristani et al. (2016) showed that more than $10 \%$ of autologous astrocytes were transdifferentiated and expressed classic neural stem cell markers after SCI. Decreased Notch signaling due to stroke was shown to be necessary for astrocyte neurogenesis (Magnusson et al., 2014). The transcription factors NeuroD1, SOX2, and ZFP521 can all be used to reprogram astrocytes into neurons or neural stem cells after SCI (Zarei-Kheirabadi et al., 2019a; Puls et al., 2020).

\section{Others}

Sodium houttuyfonate effectively inhibited the activation of microglia cells while promoting the activation of astrocytes and angiogenesis (Yao et al., 2021). Ferrostatin-1 alleviated astrocytes inflammation and ferroptosis by suppressing the ROS levels and activating the Nrf2/HO-1 signaling pathway (Li S. et al., 2021). Additionally, many other molecules, such as USP18 (Liu W. et al., 2021), p-ERK1/2 (Li et al., 2021a), CREB (Pardo et al., 2016), HSPA12B (Xia et al., 2016), CCR5 (Joy et al., 2019), also represent potential therapeutic targets that merit further investigation.

Although attention has bright prospects, the difficulty in obtaining human CNS tissue and the substantial differences between rodents and human astrocytes (Zhang et al., 2016) represent unavoidable obstacles to the identification or development of strategies for the treatment of CNS injury, that is, how to translate research results from animal studies to humans. Although astrocytes induced by human pluripotent stem cells provide a possible cell model, these astrocytes differ from astrocytes under normal physiological conditions, at least partially. How to transfer research results from animal models to human patients will likely also be the focus of research attention in the future.

\section{CONCLUSIONS}

The importance of astrocytes in CNS disease and injury is widely recognized; however, our understanding of astrocyte functions is still in its infancy. The continuous development and breakthrough of instruments and technologies provide conditions for accurate typing of astrocytes. The combination of single-cell and spatial transcriptome sequencing shows promise as a means of determining astrocyte heterogeneity after injury. Through the sequencing of several key times after injury, the time and space distribution of each astrocyte subpopulation can be determined. For example, astrocyte subpopulation D appears on the 7th day after SCI, mainly distributed in the core of injury. Further investigations to determine the temporal and spatial specificity of different astrocyte subpopulations with their specific genetic markers, thereby revealing their respective roles in injury, will provide a more precise indication to allow the targeting of specific astrocyte subpopulations for the treatment of CNS injuries. Such as the study of Hasel et al. (2021), in the mouse inflammation model, they divided astrocyte subgroups according 
to the difference between transcriptome and anatomical location and found that Cluster 8 is widely present in inflamed brains, but few in normal brains. In subsequent studies, treatment attempts can be made against Cluster 8 to inhibit the production of Cluster 8 , or convert Cluster 8 into a neuroprotective or even neutral RAs subgroup to reduce inflammation. Although they have been proposed to express unique marker genes, little is known regarding the process involved in the transformation between RAs and SAs given that research attention has primarily focused on inflammation and glial scar formation after injury. In the absence of theoretical support, there is no way to talk about the treatment of targeted SA. As detailed in this review, clarifying how SAs are generated may provide ideal treatment and management options for CNS injuries. Based on the precise type of astrocytes, targeting harmful RA subgroups in the early stage of injury to reduce neuronal death and tissue destruction, and changing the extracellular matrix and reducing scar formation through the regulation of SA in the later stage to weaken the external inhibitory factors of nerve regeneration. This kind of treatment is worth looking forward to.

\section{REFERENCES}

A, J.-C., Li, Z.-Y., Long, Q.-F., Wang, D.-Y., Zhao, H.-S., Jia, S.-L., et al. (2019). MiR-379-5p improved locomotor function recovery after spinal cord injury in rats by reducing endothelin 1 and inhibiting astrocytes expression. Eur. Rev. Med. Pharmacol. Sci. 23, 9738-9745. doi: 10.26355/eurrev_201911_19536

Abbott, N. J., Rönnbäck, L., and Hansson, E. (2006). Astrocyte-endothelial interactions at the blood-brain barrier. Nat. Rev. Neurosci. 7, 41-53. doi: $10.1038 / \mathrm{nrn} 1824$

Abdeladim, L., Matho, K. S., Clavreul, S., Mahou, P., Sintes, J. M., Solinas, X., et al. (2019). Multicolor multiscale brain imaging with chromatic multiphoton serial microscopy. Nat. Commun. 10:1662. doi: 10.1038/s41467-019-09552-9

Acarin, L., González, B., and Castellano, B. (2001). Triflusal posttreatment inhibits glial nuclear factor-kappaB, downregulates the glial response and is neuroprotective in an excitotoxic injury model in postnatal brain. Stroke 32, 2394-2402. doi: 10.1161/hs1001.097243

Adams, K. L., and Gallo, V. (2018). The diversity and disparity of the glial scar. Nat. Neurosci. 21, 9-15. doi: 10.1038/s41593-017-0033-9

Alawieh, A., Langley, E. F., Weber, S., Adkins, D., and Tomlinson, S. (2018). Identifying the role of complement in triggering neuroinflammation after traumatic brain injury. J. Neurosci. 38, 2519-2532. doi: 10.1523/JNEUROSCI. 2197-17.2018

Amiry-Moghaddam, M., Otsuka, T., Hurn, P. D., Traystman, R. J., Haug, F. M., Froehner, S. C., et al. (2003). An alpha-syntrophin-dependent pool of AQP4 in astroglial end-feet confers bidirectional water flow between blood and brain. Proc. Natl. Acad. Sci. U S A 100, 2106-2111. doi: 10.1073/pnas.0437 946100

Anderson, M. A., Burda, J. E., Ren, Y., Ao, Y., O’Shea, T. M., Kawaguchi, R., et al. (2016). Astrocyte scar formation aids central nervous system axon regeneration. Nature 532, 195-200. doi: 10.1038/nature17623

András, I. E., Deli, M. A., Veszelka, S., Hayashi, K., Hennig, B., and Toborek, M. (2007). The NMDA and AMPA/KA receptors are involved in glutamateinduced alterations of occludin expression and phosphorylation in brain endothelial cells. J. Cereb. Blood Flow Metab. 27, 1431-1443. doi: 10.1038/sj. jcbfm. 9600445

Arellano, J. I., Morozov, Y. M., Micali, N., and Rakic, P. (2021). Radial glial cells: new views on old questions. Neurochem. Res. 46, 2512-2524. doi: 10.1007/s11064-021-03296-Z

Babaee, A., Eftekhar-Vaghefi, S. H., Asadi-Shekaari, M., Shahrokhi, N., Soltani, S. D., Malekpour-Afshar, R., et al. (2015). Melatonin treatment reduces

\section{AUTHOR CONTRIBUTIONS}

$\mathrm{BN}$ designed the research and revised the manuscript. $\mathrm{YZ}$ found some articles. GY wrote the article. All authors contributed to the article and approved the submitted version.

\section{FUNDING}

Grant support was provided by the National Natural Science Fund of China (Nos. 81771346, 82071383), Natural Science Foundation of Shandong Province (Key Project No. ZR2020KH007), the Taishan Scholar Youth Program of Shandong Province (tsqn201812156), Academic Promotion Program of Shandong First Medical University (2019QL025, 2019RC021), Spring Industry Leader Talent Support Plan (No. 201984), and Rongxiang Regenerative Medicine Fund (2019SDRX-23).

\section{ACKNOWLEDGMENTS}

We thank all the funding sources. The cell model in the picture comes from the BioRender APP.

astrogliosis and apoptosis in rats with traumatic brain injury. Iran. J. Basic Med. Sci. 18, 867-872. doi: 10.22038/IJBMS.2015.5207

Badhiwala, J. H., Wilson, J. R., and Fehlings, M. G. (2019). Global burden of traumatic brain and spinal cord injury. Lancet Neurol. 18, 24-25. doi: 10.1016/S1474-4422(18)30444-7

Bake, S., Okoreeh, A. K., Alaniz, R. C., and Sohrabji, F. (2016). Insulin-like growth factor (IGF)-I modulates endothelial blood-brain barrier function in ischemic middle-aged female rats. Endocrinology 157, 61-69. doi: 10.1210/en.2015-1840

Bake, S., Okoreeh, A., Khosravian, H., and Sohrabji, F. (2019). Insulin-like Growth Factor (IGF)-1 treatment stabilizes the microvascular cytoskeleton under ischemic conditions. Exp. Neurol. 311, 162-172. doi: 10.1016/j.expneurol.2018. 09.016

Bao, Y., Qin, L., Kim, E., Bhosle, S., Guo, H., Febbraio, M., et al. (2012). CD36 is involved in astrocyte activation and astroglial scar formation. J. Cereb. Blood Flow Metab. 32, 1567-1577. doi: 10.1038/jcbfm.2012.52

Basiri, M., and Doucette, R. (2010). Sensorimotor cortex aspiration: a model for studying Wallerian degeneration-induced glial reactivity along the entire length of a single CNS axonal pathway. Brain Res. Bull. 81, 43-52. doi: 10.1016/j. brainresbull.2009.11.002

Beitchman, J. A., Griffiths, D. R., Hur, Y., Ogle, S. B., Bromberg, C. E., Morrison, H. W., et al. (2020). Experimental traumatic brain injury induces chronic glutamatergic dysfunction in amygdala circuitry known to regulate anxiety-like behavior. Front. Neurosci. 13:1434. doi: 10.3389/fnins.2019.01434

Bekar, L. K., He, W., and Nedergaard, M. (2008). Locus coeruleus alphaadrenergic-mediated activation of cortical astrocytes in vivo. Cereb. Cortex 18 , 2789-2795. doi: 10.1093/cercor/bhn040

Berninger, B., Costa, M. R., Koch, U., Schroeder, T., Sutor, B., Grothe, B., et al. (2007). Functional properties of neurons derived from in vitro reprogrammed postnatal astroglia. J. Neurosci. 27, 8654-8664. doi: 10.1523/JNEUROSCI.161507.2007

Boisvert, M. M., Erikson, G. A., Shokhirev, M. N., and Allen, N. J. (2018). The aging astrocyte transcriptome from multiple regions of the mouse brain. Cell Rep. 22, 269-285. doi: 10.1016/j.celrep.2017.12.039

Bourguignon, L. Y., Gilad, E., Peyrollier, K., Brightman, A., and Swanson, R. A. (2007). Hyaluronan-CD44 interaction stimulates Racl signaling and PKN gamma kinase activation leading to cytoskeleton function and cell migration in astrocytes. J. Neurochem. 101, 1002-1017. doi: 10.1111/j.1471-4159.2007. 04485.x

Bradbury, E. J., and Burnside, E. R. (2019). Moving beyond the glial scar for spinal cord repair. Nat. Commun. 10:3879. doi: 10.1038/s41467-019-11707-7 
Bradbury, E. J., Moon, L. D., Popat, R. J., King, V. R., Bennett, G. S., Patel, P. N., et al. (2002). Chondroitinase $A B C$ promotes functional recovery after spinal cord injury. Nature 416, 636-640. doi: 10.1038/416636a

Brambilla, R., Bracchi-Ricard, V., Hu, W. H., Frydel, B., Bramwell, A., Karmally, S., et al. (2005). Inhibition of astroglial nuclear factor kappaB reduces inflammation and improves functional recovery after spinal cord injury. J. Exp. Med. 202, 145-156. doi: 10.1084/jem.20041918

Burda, J. E., Bernstein, A. M., and Sofroniew, M. V. (2016). Astrocyte roles in traumatic brain injury. Exp. Neurol. 275, 305-315. doi: 10.1016/j.expneurol. 2015.03.020

Burda, J. E., and Sofroniew, M. V. (2014). Reactive gliosis and the multicellular response to CNS damage and disease. Neuron 81, 229-248. doi: 10.1016/j. neuron.2013.12.034

Buskila, Y., Abu-Ghanem, Y., Levi, Y., Moran, A., Grauer, E., and Amitai, Y. (2007). Enhanced astrocytic nitric oxide production and neuronal modifications in the neocortex of a NOS2 mutant mouse. PLoS One 2:e843. doi: 10.1371/journal.pone.0000843

Cao, L. L., Guan, P. P., Zhang, S. Q., Yang, Y., Huang, X. S., and Wang, P. (2021). Downregulating expression of OPTN elevates neuroinflammation via AIM2 inflammasome- and RIPK1-activating mechanisms in APP/PS1 transgenic mice. J. Neuroinflammation 18:281. doi: 10.1186/s12974021-02327-4

Chan, S. J., Niu, W., Hayakawa, K., Hamanaka, G., Wang, X., Cheah, P. S., et al. (2019). Promoting neuro-supportive properties of astrocytes with epidermal growth factor hydrogels. Stem Cells Transl. Med. 8, 1242-1248. doi: 10.1002/sctm.19-0159

Chao, H., Liu, Y., Lin, C., Xu, X., Li, Z., Bao, Z., et al. (2018). Activation of bradykinin B2 receptor induced the inflammatory responses of cytosolic phospholipase $\mathrm{A}(2)$ after the early traumatic brain injury. Biochim. Biophys. Acta Mol. Basis Dis. 1864, 2957-2971. doi: 10.1016/j.bbadis.2018. 06.006

Charkviani, M., Muradashvili, N., Sulimai, N., and Lominadze, D. (2020). Fibrinogen-cellular prion protein complex formation on astrocytes. J. Neurophysiol. 124, 536-543. doi: 10.1152/jn.00224.2020

Cheli, V. T., Santiago González, D. A., Smith, J., Spreuer, V., Murphy, G. G., and Paez, P. M. (2016). L-type voltage-operated calcium channels contribute to astrocyte activation in vitro. Glia 64, 1396-1415. doi: 10.1002/glia.23013

Chen, M., Guo, L., Hao, J., Ni, J., Lv, Q., Xin, X., et al. (2020). p75NTR promotes astrocyte proliferation in response to cortical stab wound. Cell. Mol. Neurobiol. doi: 10.1007/s10571-020-01006-x. [Online ahead of print].

Cheng, Z. J., Dai, T. M., Shen, Y. Y., He, J. L., Li, J., and Tu, J. L. (2018). Atorvastatin pretreatment attenuates ischemic brain edema by suppressing aquaporin 4 . J. Stroke Cerebrovasc. Dis. 27, 3247-3255. doi: 10.1016/j.jstrokecerebrovasdis. 2018.07.011

Clark, D. P. Q., Perreau, V. M., Shultz, S. R., Brady, R. D., Lei, E., Dixit, S., et al. (2019). Inflammation in traumatic brain injury: roles for toxic A1 astrocytes and microglial-astrocytic crosstalk. Neurochem. Res. 44, 1410-1424. doi: 10.1007/s11064-019-02721-8

Clarke, L. E., Liddelow, S. A., Chakraborty, C., Münch, A. E., Heiman, M., and Barres, B. A. (2018). Normal aging induces A1-like astrocyte reactivity. Proc. Natl. Acad. Sci. U S A 115, E1896-E1905. doi: 10.1073/pnas.1800165115

Codeluppi, S., Svensson, C. I., Hefferan, M. P., Valencia, F., Silldorff, M. D., Oshiro, M., et al. (2009). The Rheb-mTOR pathway is upregulated in reactive astrocytes of the injured spinal cord. J. Neurosci. 29, 1093-1104. doi: 10.1523/JNEUROSCI.4103-08.2009

Colavincenzo, J., and Levine, R. L. (2000). Myelin debris clearance during Wallerian degeneration in the goldfish visual system. J. Neurosci. Res. 59, 47-62. doi: 10.1002/(SICI)1097-4547(20000101)59:1<47::AID-JNR7>3.0.CO;2-P

Corti, S., Nizzardo, M., Simone, C., Falcone, M., Donadoni, C., Salani, S., et al. (2012). Direct reprogramming of human astrocytes into neural stem cells and neurons. Exp. Cell Res. 318, 1528-1541. doi: 10.1016/j.yexcr.2012. 02.040

Das, S., Li, Z., Noori, A., Hyman, B. T., and Serrano-Pozo, A. (2020). Meta-analysis of mouse transcriptomic studies supports a context-dependent astrocyte reaction in acute CNS injury versus neurodegeneration. J. Neuroinflammation 17:227. doi: 10.1186/s12974-020-01898-y

de Amorim, V. C. M., Júnior, M. S. O., da Silva, A. B., David, J. M., David, J. P. L., de Fátima Dias Costa, M., et al. (2020). Agathisflavone modulates astrocytic responses and increases the population of neurons in an in vitro model of traumatic brain injury. Naunyn Schmiedebergs Arch. Pharmacol. 393, 1921-1930. doi: 10.1007/s00210-020-01905-2

Diaz, A., Martin-Jimenez, C., Xu, Y., Merino, P., Woo, Y., Torre, E., et al. (2021). Urokinase-type plasminogen activator-mediated crosstalk between $\mathrm{N}$-cadherin and $\beta$-catenin promotes wound healing. J. Cell Sci. 134:jcs255919. doi: $10.1242 /$ jcs. 255919

Du, N., Li, H., Sun, C., He, B., Yang, T., Song, H., et al. (2021). Adult astrocytes from reptiles are resistant to proinflammatory activation via sustaining Vav1 expression. J. Biol. Chem. 296:100527. doi: 10.1016/j.jbc.2021.100527

Early, A. N., Gorman, A. A., Van Eldik, L. J., Bachstetter, A. D., and Morganti, J. M. (2020). Effects of advanced age upon astrocyte-specific responses to acute traumatic brain injury in mice. J. Neuroinflammation 17:115 doi: 10.1186/s12974-020-01800-w

Escartin, C., Galea, E., Lakatos, A., O'Callaghan, J. P., Petzold, G. C., SerranoPozo, A., et al. (2021). Reactive astrocyte nomenclature, definitions and future directions. Nat. Neurosci. 24, 312-325. doi: 10.1038/s41593-020-00783-4

Farr, G. W., Hall, C. H., Farr, S. M., Wade, R., Detzel, J. M., Adams, A. G. et al. (2019). Functionalized phenylbenzamides inhibit aquaporin-4 reducing cerebral edema and improving outcome in two models of CNS injury. Neuroscience 404, 484-498. doi: 10.1016/j.neuroscience.2019.01.034

Faulkner, J. R., Herrmann, J. E., Woo, M. J., Tansey, K. E., Doan, N. B., and Sofroniew, M. V. (2004). Reactive astrocytes protect tissue and preserve function after spinal cord injury. J. Neurosci. 24, 2143-2155. doi: 10.1523/JNEUROSCI.3547-03.2004

Finnie, J. W., Blumbergs, P. C., and Manavis, J. (2011). Aquaporin-4 expression after experimental contusional injury in an ovine impact-acceleration head injury model. J. Clin. Neurosci. 18, 947-950. doi: 10.1016/j.jocn.2010.11.010

Finsterwald, C., Dias, S., Magistretti, P. J., and Lengacher, S. (2021). Ganglioside GM1 targets astrocytes to stimulate cerebral energy metabolism. Front. Pharmacol. 12:653842. doi: 10.3389/fphar.2021.653842

Förstner, P., Rehman, R., Anastasiadou, S., Haffner-Luntzer, M., Sinske, D., Ignatius, A., et al. (2018). Neuroinflammation after traumatic brain injury is enhanced in activating transcription factor 3 mutant mice. J. Neurotrauma 35, 2317-2329. doi: 10.1089/neu.2017.5593

Gaetz, M. (2004). The neurophysiology of brain injury. Clin. Neurophysiol. 115, 4-18. doi: 10.1016/s1388-2457(03)00258-x

Gao, W., Zhao, Z., Yu, G., Zhou, Z., Zhou, Y., Hu, T., et al. (2015). VEGI attenuates the inflammatory injury and disruption of blood-brain barrier partly by suppressing the TLR4/NF- $\mathrm{B}$ signaling pathway in experimental traumatic brain injury. Brain Res. 1622, 230-239. doi: 10.1016/j.brainres.2015. 04.035

García-Alías, G., Barkhuysen, S., Buckle, M., and Fawcett, J. W. (2009). Chondroitinase $\mathrm{ABC}$ treatment opens a window of opportunity for task-specific rehabilitation. Nat. Neurosci. 12, 1145-1151. doi: 10.1016/j.onehlt. 2021.100325

Gayen, M., Bhomia, M., Balakathiresan, N., and Knollmann-Ritschel, B. (2020). Exosomal microRNAs released by activated astrocytes as potential neuroinflammatory biomarkers. Int. J. Mol. Sci. 21:2312 doi: 10.3390/ijms21072312

GBD 2016 Traumatic Brain Injury and Spinal Cord Injury Collaborators. (2019). Global, regional and national burden of traumatic brain injury and spinal cord injury, 1990-2016: a systematic analysis for the Global Burden of Disease Study 2016. Lancet Neurol. 18, 56-87. doi: 10.1016/S1474-4422(18)30415-0

Ge, W. P., Miyawaki, A., Gage, F. H., Jan, Y. N., and Jan, L. Y. (2012). Local generation of glia is a major astrocyte source in postnatal cortex. Nature 484, 376-380. doi: 10.1038/nature10959

Gerzanich, V., Stokum, J. A., Ivanova, S., Woo, S. K., Tsymbalyuk, O., Sharma, A., et al. (2019). Sulfonylurea receptor 1, transient receptor potential cation channel subfamily $M$ member 4 and KIR6.2:role in hemorrhagic progression of contusion. J. Neurotrauma 36, 1060-1079. doi: 10.1089/neu.20 18.5986

Goodus, M. T., Kerr, N. A., Talwar, R., Buziashvili, D., Fragale, J. E., Pang, K. C. et al. (2016). Leukemia inhibitory factor haplodeficiency desynchronizes glial reactivity and exacerbates damage and functional deficits after a concussive brain injury. J. Neurotrauma 33, 1522-1534. doi: 10.1089/neu.2015.4234

Goodwin, A. E., and Grizzle, J. M. (1994). Endogenous enzymes cause structural and chemical artifacts in methacrylate- and celloidin-embedded 
sections of unfixed freeze-dried tissues. J. Histochem. Cytochem. 42, 109-114. doi: $10.1177 / 42.1 .7505299$

Gottipati, M. K., D’Amato, A. R., Ziemba, A. M., Popovich, P. G., and Gilbert, R. J. (2020). TGF 33 is neuroprotective and alleviates the neurotoxic response induced by aligned poly-l-lactic acid fibers on naïve and activated primary astrocytes. Acta Biomater. 117, 273-282. doi: 10.1016/j.actbio.2020.09.057

Gu, Y., Cheng, X., Huang, X., Yuan, Y., Qin, S., Tan, Z., et al. (2019). Conditional ablation of reactive astrocytes to dissect their roles in spinal cord injury and repair. Brain Behav. Immun. 80, 394-405. doi: 10.1016/j.bbi.2019.04.016

Gu, Y., Zheng, G., Xu, M., Li, Y., Chen, X., Zhu, W., et al. (2012). Caveolin1 regulates nitric oxide-mediated matrix metalloproteinases activity and bloodbrain barrier permeability in focal cerebral ischemia and reperfusion injury. J. Neurochem. 120, 147-156. doi: 10.1111/j.1471-4159.2011.07542.x

Guo, Q., Li, S., Liang, Y., Zhang, Y., Zhang, J., Wen, C., et al. (2010). Effects of C3 deficiency on inflammation and regeneration following spinal cord injury in mice. Neurosci. Lett. 485, 32-36. doi: 10.1016/j.neulet.2010.08.056

Guttenplan, K. A., Weigel, M. K., Prakash, P., Wijewardhane, P. R., Hasel, P., Rufen-Blanchette, U., et al. (2021). Neurotoxic reactive astrocytes induce cell death via saturated lipids. Nature 599, 102-107. doi: 10.1038/s41586-02103960-y

Gwak, Y. S., Kang, J., Unabia, G. C., and Hulsebosch, C. E. (2012). Spatial and temporal activation of spinal glial cells: role of gliopathy in central neuropathic pain following spinal cord injury in rats. Exp. Neurol. 234, 362-372. doi: 10.1016/j.expneurol.2011.10.010

Gyoneva, S., and Ransohoff, R. M. (2015). Inflammatory reaction after traumatic brain injury: therapeutic potential of targeting cell-cell communication by chemokines. Trends Pharmacol. Sci. 36, 471-480. doi: 10.1016/j.tips.2015.04. 003

Han, Q., Xie, Y., Ordaz, J. D., Huh, A. J., Huang, N., Wu, W., et al. (2020). Restoring cellular energetics promotes axonal regeneration and functional recovery after spinal cord injury. Cell Metab. 31, 623-641.e8. doi: 10.1016/j. cmet.2020.02.002

Hara, M., Kobayakawa, K., Ohkawa, Y., Kumamaru, H., Yokota, K., Saito, T., et al. (2017). Interaction of reactive astrocytes with type I collagen induces astrocytic scar formation through the integrin-N-cadherin pathway after spinal cord injury. Nat. Med. 23, 818-828. doi: 10.1038/nm.4354

Hasel, P., Rose, I. V. L., Sadick, J. S., Kim, R. D., and Liddelow, S. A. (2021). Neuroinflammatory astrocyte subtypes in the mouse brain. Nat. Neurosci. 24, 1475-1487. doi: 10.1038/s41593-021-00905-6

Heins, N., Malatesta, P., Cecconi, F., Nakafuku, M., Tucker, K. L., Hack, M. A., et al. (2002). Glial cells generate neurons: the role of the transcription factor Pax6. Nat. Neurosci. 5, 308-315. doi: 10.1038/nn828

Hemley, S. J., Bilston, L. E., Cheng, S., Chan, J. N., and Stoodley, M. A. (2013). Aquaporin-4 expression in post-traumatic syringomyelia. J. Neurotrauma 30, 1457-1467. doi: 10.1089/neu.2012.2614

Herrmann, J. E., Imura, T., Song, B., Qi, J., Ao, Y., Nguyen, T. K., et al. (2008). STAT3 is a critical regulator of astrogliosis and scar formation after spinal cord injury. J. Neurosci. 28, 7231-7243. doi: 10.1523/JNEUROSCI.1709-08.2008

Hlavac, N., Guilhaume-Corrêa, F., and VandeVord, P. J. (2020). Mechanostimulation initiated by extracellular adhesion and cationic conductance pathways influence astrocyte activation. Neurosci. Lett. 739:135405. doi: 10.1016/j.neulet.2020.135405

Hlavac, N., and VandeVord, P. J. (2019). Astrocyte mechano-activation by high-rate overpressure involves alterations in structural and junctional proteins. Front. Neurol. 10:99. doi: 10.3389/fneur.2019.00099

Hong, P., Jiang, M., and Li, H. (2014). Functional requirement of dicer1 and miR$17-5 \mathrm{p}$ in reactive astrocyte proliferation after spinal cord injury in the mouse. Glia 62, 2044-2060. doi: 10.1002/glia.22725

Hossain-Ibrahim, M. K., Rezajooi, K., Stallcup, W. B., Lieberman, A. R., and Anderson, P. N. (2007). Analysis of axonal regeneration in the central and peripheral nervous systems of the NG2-deficient mouse. BMC Neurosci. 8:80. doi: 10.1186/1471-2202-8-80

Hsu, J. Y., Bourguignon, L. Y., Adams, C. M., Peyrollier, K., Zhang, H., Fandel, T., et al. (2008). Matrix metalloproteinase-9 facilitates glial scar formation in the injured spinal cord. J. Neurosci. 28, 13467-13477. doi: 10.1523/JNEUROSCI. 2287-08.2008

Huang, C., Sakry, D., Menzel, L., Dangel, L., Sebastiani, A., Krämer, T., et al. (2016). Lack of NG2 exacerbates neurological outcome and modulates glial responses after traumatic brain injury. Glia 64, 507-523. doi: 10.1002/glia. 22944

Ishiguro, H., Kaito, T., Hashimoto, K., Kushioka, J., Okada, R., Tsukazaki, H., et al. (2019). Administration of ONO-2506 suppresses neuropathic pain after spinal cord injury by inhibition of astrocytic activation. Spine J. 19, 1434-1442. doi: 10.1016/j.spinee.2019.04.006

Ito, H., Yamamoto, N., Arima, H., Hirate, H., Morishima, T., Umenishi, F., et al (2006). Interleukin-1beta induces the expression of aquaporin-4 through a nuclear factor-kappaB pathway in rat astrocytes. J. Neurochem. 99, 107-118. doi: 10.1111/j.1471-4159.2006.04036.x

Jacobsen, C. T., and Miller, R. H. (2003). Control of astrocyte migration in the developing cerebral cortex. Dev. Neurosci. 25, 207-216. doi: 10.1159/000072269

Jamjoom, A. A. B., Rhodes, J., Andrews, P. J. D., and Grant, S. G. N. (2021). The synapse in traumatic brain injury. Brain 144, 18-31. doi: 10.1093/brain/awaa321

Jayakumar, A. R., Panickar, K. S., Curtis, K. M., Tong, X. Y., Moriyama, M., and Norenberg, M. D. (2011). Na-K-Cl cotransporter-1 in the mechanism of cell swelling in cultured astrocytes after fluid percussion injury. J. Neurochem. 117, 437-448. doi: 10.1111/j.1471-4159.2011.07211.x

Ji, H., Zhang, Y., Chen, C., Li, H., He, B., Yang, T., et al. (2021). Ddopachrome tautomerase activates $\mathrm{COX} 2 / \mathrm{PGE}(2)$ pathway of astrocytes to mediate inflammation following spinal cord injury. J. Neuroinflammation 18:130. doi: 10.1186/s12974-021-02186-Z

Jia, S. W., Liu, X. Y., Wang, S. C., and Wang, Y. F. (2016). Vasopressin hypersecretion-associated brain edema formation in ischemic stroke: underlying mechanisms. J. Stroke Cerebrovasc. Dis. 25, 1289-1300. doi: 10.1016/j.jstrokecerebrovasdis.2016.02.002

Jiang, D., Gong, F., Ge, X., Lv, C., Huang, C., Feng, S., et al. (2020). Neuron-derived exosomes-transmitted miR-124-3p protect traumatically injured spinal cord by suppressing the activation of neurotoxic microglia and astrocytes. J. Nanobiotechnology 18:105. doi: 10.1186/s12951-020 $-00665-8$

Jiang, Z., Li, C., Arrick, D. M., Yang, S., Baluna, A. E., and Sun, H. (2014) Role of nitric oxide synthases in early blood-brain barrier disruption following transient focal cerebral ischemia. PLoS One 9:e93134. doi: 10.1371/journal. pone.0093134

Jiang, T., Luo, J., Pan, X., Zheng, H., Yang, H., Zhang, L., et al. (2021) Physical exercise modulates the astrocytes polarization, promotes myelin debris clearance and remyelination in chronic cerebral hypoperfusion rats. Life Sci. 278:119526. doi: 10.1016/j.lfs.2021.119526

Jing, N., Fang, B., Li, Z., and Tian, A. (2020). Exogenous activation of cannabinoid-2 receptor modulates TLR4/MMP9 expression in a spinal cord ischemia reperfusion rat model. J. Neuroinflammation 17:101. doi: 10.1186/s12974-020-01784-7

Johnson, V. E., Stewart, W., and Smith, D. H. (2013). Axonal pathology in traumatic brain injury. Exp. Neurol. 246, 35-43. doi: 10.1016/j.expneurol.2012. 01.013

Joy, M. T., Ben Assayag, E., Shabashov-Stone, D., Liraz-Zaltsman, S., Mazzitelli, J., Arenas, M., et al. (2019). CCR5 is a therapeutic target for recovery after stroke and traumatic brain injury. Cell 176, 1143-1157.e13. doi: 10.1016/j.cell.2019.01. 044

Kabadi, S. V., Stoica, B. A., Zimmer, D. B., Afanador, L., Duffy, K. B., Loane, D. J., et al. (2015). S100B inhibition reduces behavioral and pathologic changes in experimental traumatic brain injury. J. Cereb. Blood Flow Metab. 35, 2010-2020. doi: 10.1038/jcbfm.2015.165

Kaminski, N., Köster, C., Mouloud, Y., Börger, V., Felderhoff-Müser, U., Bendix, I., et al. (2020). Mesenchymal stromal cell-derived extracellular vesicles reduce neuroinflammation, promote neural cell proliferation and improve oligodendrocyte maturation in neonatal hypoxic-ischemic brain injury. Front. Cell. Neurosci. 14:601176. doi: 10.3389/fncel.2020.601176

Kang, W., Balordi, F., Su, N., Chen, L., Fishell, G., and Hébert, J. M. (2014) Astrocyte activation is suppressed in both normal and injured brain by FGF signaling. Proc. Natl. Acad. Sci. U S A 111, E2987-E2995. doi: 10.1073/pnas. 1320401111

Kapoor, S., Kim, S. M., Farook, J. M., Mir, S., Saha, R., and Sen, N. (2013). Foxo3a transcriptionally upregulates AQP4 and induces cerebral edema following traumatic brain injury. J. Neurosci. 33, 17398-17403. doi: 10.1523/JNEUROSCI.2756-13.2013 
Karve, I. P., Taylor, J. M., and Crack, P. J. (2016). The contribution of astrocytes and microglia to traumatic brain injury. Br. J. Pharmacol. 173, 692-702. doi: 10.1111/bph.13125

Kerr, B. J., and Patterson, P. H. (2004). Potent pro-inflammatory actions of leukemia inhibitory factor in the spinal cord of the adult mouse. Exp. Neurol. 188, 391-407. doi: 10.1016/j.expneurol.2004.04.012

Kigerl, K. A., de Rivero Vaccari, J. P., Dietrich, W. D., Popovich, P. G., and Keane, R. W. (2014). Pattern recognition receptors and central nervous system repair. Exp. Neurol. 258, 5-16. doi: 10.1016/j.expneurol.2014.01.001

Kitchen, P., Day, R. E., Taylor, L. H., Salman, M. M., Bill, R. M., Conner, M. T., et al. (2015). Identification and molecular mechanisms of the rapid tonicity-induced relocalization of the aquaporin 4 channel. J. Biol. Chem. 290, 16873-16881. doi: 10.1074/jbc.M115.646034

Kitchen, P., Salman, M. M., Halsey, A. M., Clarke-Bland, C., MacDonald, J. A., Ishida, H., et al. (2020). Targeting aquaporin-4 subcellular localization to treat central nervous system edema. Cell 181, 784-799.e19. doi: 10.1016/j.cell.2020. 03.037

Kong, L., Wang, Y., Wang, X. J., Wang, X. T., Zhao, Y., Wang, L. M., et al. (2015). Retinoic acid ameliorates blood-brain barrier disruption following ischemic stroke in rats. Pharmacol. Res. 99, 125-136. doi: 10.1016/j.phrs.2015. 05.014

Koyama, Y. (2014). Signaling molecules regulating phenotypic conversions of astrocytes and glial scar formation in damaged nerve tissues. Neurochem. Int. 78, 35-42. doi: 10.1016/j.neuint.2014.08.005

Koyama, Y. (2021). Endothelin ET(B) receptor-mediated astrocytic activation: pathological roles in brain disorders. Int. J. Mol. Sci. 22:4333. doi: 10.3390/ijms22094333

Kriegstein, A., and Alvarez-Buylla, A. (2009). The glial nature of embryonic and adult neural stem cells. Annu. Rev. Neurosci. 32, 149-184. doi: 10.1146/annurev. neuro.051508.135600

Lang, B. T., Cregg, J. M., DePaul, M. A., Tran, A. P., Xu, K., Dyck, S. M., et al. (2015). Modulation of the proteoglycan receptor PTP $\sigma$ promotes recovery after spinal cord injury. Nature 518, 404-408. doi: 10.1038/nature13974

LaPlaca, M. C., Prado, G. R., Cullen, D., and Simon, C. M. (2009). Plasma membrane damage as a marker of neuronal injury. Annu. Int. Conf. IEEE Eng. Med. Biol. Soc. 2009, 1113-1116. doi: 10.1109/IEMBS.2009.5334457

Lenhossék, M. (1893). Der Feinere Bau Des Nervensystems Im Lichte Neuester Forschungen. Berlin: Fischer.

Lepore, A. C., O’Donnell, J., Bonner, J. F., Paul, C., Miller, M. E., Rauck, B., et al. (2011a). Spatial and temporal changes in promoter activity of the astrocyte glutamate transporter GLT1 following traumatic spinal cord injury. J. Neurosci. Res. 89, 1001-1017. doi: 10.1002/jnr.22624

Lepore, A. C., O’Donnell, J., Kim, A. S., Yang, E. J., Tuteja, A., Haidet-Phillips, A., et al. (2011b). Reduction in expression of the astrocyte glutamate transporter, GLT1, worsens functional and histological outcomes following traumatic spinal cord injury. Glia 59, 1996-2005. doi: 10.1002/glia.21241

Levison, S. W., and Goldman, J. E. (1993). Both oligodendrocytes and astrocytes develop from progenitors in the subventricular zone of postnatal rat forebrain. Neuron 10, 201-212. doi: 10.1016/0896-6273(93)90311-e

Li, K., Javed, E., Hala, T. J., Sannie, D., Regan, K. A., Maragakis, N. J., et al. (2015). Transplantation of glial progenitors that overexpress glutamate transporter GLT1 preserves diaphragm function following cervical SCI. Mol. Ther. 23, 533-548. doi: 10.1038/mt.2014.236

Li, J., Jia, Z., Xu, W., Guo, W., Zhang, M., Bi, J., et al. (2019). TGN-020 alleviates edema and inhibits astrocyte activation and glial scar formation after spinal cord compression injury in rats. Life Sci. 222, 148-157. doi: 10.1016/j.lfs.2019. 03.007

Li, J., Jia, Z., Zhang, Q., Dai, J., Kong, J., Fan, Z., et al. (2021a). Inhibition of ERK1/2 phosphorylation attenuates spinal cord injury induced astrocyte activation and inflammation through negatively regulating aquaporin-4 in rats. Brain Res. Bull. 170, 162-173. doi: 10.1016/j.brainresbull.2021. 02.014

Li, J., Wang, X., and Qin, S. (2021b). Molecular mechanisms and signaling pathways of reactive astrocytes responding to traumatic brain injury. Histol. Histopathol doi: 10.14670/HH -18-338. [Online ahead of print].

Li, H., Kong, R., Wan, B., Yang, L., Zhang, S., Cao, X., et al. (2020). Initiation of PI3K/AKT pathway by IGF-1 decreases spinal cord injury-induced endothelial apoptosis and microvascular damage. Life Sci. 263:118572. doi: 10.1016/j.lfs. 2020.118572

Li, P., Li, Y., Dai, Y., Wang, B., Li, L., Jiang, B., et al. (2020). The LncRNA H19/miR1-3p/CCL2 axis modulates lipopolysaccharide (LPS) stimulation-induced normal human astrocyte proliferation and activation. Cytokine 131:155106. doi: 10.1016/j.cyto.2020.155106

Li, L., Li, Y., He, B., Li, H., Ji, H., Wang, Y., et al. (2021). HSF1 is involved in suppressing A1 phenotype conversion of astrocytes following spinal cord injury in rats. J. Neuroinflammation 18:205. doi: 10.1186/s12974-021 $-02271-3$

Li, X., Li, M., Tian, L., Chen, J., Liu, R., and Ning, B. (2020). Reactive astrogliosis: implications in spinal cord injury progression and therapy. Oxid. Med. Cell. Longev. 2020:9494352. doi: 10.1155/2020/9494352

Li, Z. W., Li, J. J., Wang, L., Zhang, J. P., Wu, J. J., Mao, X. Q., et al. (2014). Epidermal growth factor receptor inhibitor ameliorates excessive astrogliosis and improves the regeneration microenvironment and functional recovery in adult rats following spinal cord injury. J. Neuroinflammation 11:71. doi: 10.1186/1742-2094-11-71

Li, B., Mahmood, A., Lu, D., Wu, H., Xiong, Y., Qu, C., et al. (2009). Simvastatin attenuates microglial cells and astrocyte activation and decreases interleukin-1beta level after traumatic brain injury. Neurosurgery 65, 179-185. doi: 10.1227/01.NEU.0000346272.76537.DC

Li, K., Nicaise, C., Sannie, D., Hala, T. J., Javed, E., Parker, J. L., et al. (2014). Overexpression of the astrocyte glutamate transporter GLT1 exacerbates phrenic motor neuron degeneration, diaphragm compromise and forelimb motor dysfunction following cervical contusion spinal cord injury. J. Neurosci. 34, 7622-7638. doi: 10.1523/JNEUROSCI.4690 $-13.2014$

Li, Q. X., Shen, Y. X., Ahmad, A., Shen, Y. J., Zhang, Y. Q., Xu, P. K., et al. (2018) Mesencephalic astrocyte-derived neurotrophic factor prevents traumatic brain injury in rats by inhibiting inflammatory activation and protecting the bloodbrain barrier. World Neurosurg. 117, e117-e129. doi: 10.1016/j.wneu.2018. 05.202

Li, J., Wang, H., Du, C., Jin, X., Geng, Y., Han, B., et al. (2020). hUCMSCs ameliorated CUMS-induced depression by modulating complement C3 signaling-mediated microglial polarization during astrocyte-microglia crosstalk. Brain Res. Bull. 163, 109-119. doi: 10.1016/j.brainresbull.2020. 07.004

Li, S., Zhou, C., Zhu, Y., Chao, Z., Sheng, Z., Zhang, Y., et al. (2021). Ferrostatin1 alleviates angiotensin II (Ang II)- induced inflammation and ferroptosis in astrocytes. Int. Immunopharmacol. 90:107179. doi: 10.1016/j.intimp.2020. 107179

Lian, H., Yang, L., Cole, A., Sun, L., Chiang, A. C., Fowler, S. W., et al. (2015) NFKB-activated astroglial release of complement C3 compromises neuronal morphology and function associated with Alzheimer's disease. Neuron 85, 101-115. doi: 10.1016/j.neuron.2014.11.018

Liang, D., Bhatta, S., Gerzanich, V., and Simard, J. M. (2007). Cytotoxic edema: mechanisms of pathological cell swelling. Neurosurg. Focus 22:E2. doi: $10.3171 /$ foc.2007.22.5.3

Liang, J., Takeuchi, H., Doi, Y., Kawanokuchi, J., Sonobe, Y., Jin, S., et al. (2008). Excitatory amino acid transporter expression by astrocytes is neuroprotective against microglial excitotoxicity. Brain Res. 1210, 11-19. doi: 10.1016/j. brainres.2008.03.012

Liddelow, S. A., and Barres, B. A. (2017). Reactive astrocytes: production, function and therapeutic potential. Immunity 46, 957-967. doi: 10.1016/j.immuni.2017. 06.006

Liddelow, S. A., Guttenplan, K. A., Clarke, L. E., Bennett, F. C., Bohlen, C. J., Schirmer, L., et al. (2017). Neurotoxic reactive astrocytes are induced by activated microglia. Nature 541, 481-487. doi: 10.1038/nature21029

Lima, R., Gomes, E. D., Cibrão, J. R., Rocha, L. A., Assunção-Silva, R. C., Rodrigues, C. S., et al. (2021). Levetiracetam treatment leads to functional recovery after thoracic or cervical injuries of the spinal cord. NPJ Regen. Med. 6:11. doi: 10.1038/s41536-021-00121-7

Lin, C. H., Chen, H. Y., and Wei, K. C. (2020). Role of HMGB1/TLR4 axis in ischemia/reperfusion-impaired extracellular glutamate clearance in primary astrocytes. Cells 9:2585. doi: 10.3390/cells9122585

Linnerbauer, M., Wheeler, M. A., and Quintana, F. J. (2020). Astrocyte crosstalk in CNS inflammation. Neuron 108, 608-622. doi: 10.1016/j.neuron.2020.08.012 
Liraz-Zaltsman, S., Friedman-Levi, Y., Shabashov-Stone, D., Gincberg, G., Atrakcy-Baranes, D., Joy, M. T., et al. (2021). Chemokine receptors CC chemokine receptor 5 and $\mathrm{C}-\mathrm{X}-\mathrm{C}$ motif chemokine receptor 4 are new therapeutic targets for brain recovery after traumatic brain injury. J. Neurotrauma 38, 2003-2017. doi: 10.1089/neu.2020.7015

Litvinchuk, A., Wan, Y. W., Swartzlander, D. B., Chen, F., Cole, A., Propson, N. E., et al. (2018). Complement C3aR inactivation attenuates tau pathology and reverses an immune network deregulated in tauopathy models and Alzheimer's disease. Neuron 100, 1337-1353.e5. doi: 10.1016/j.neuron.2018.10.031

Liu, Z. H., Chen, N. Y., Tu, P. H., Wu, C. T., Chiu, S. C., Huang, Y. C., et al. (2020). DHA attenuates cerebral edema following traumatic brain injury via the reduction in blood-brain barrier permeability. Int. J. Mol. Sci. 21:6291. doi: 10.3390/ijms21176291

Liu, W., Ge, X., Zhou, Z., Jiang, D., Rong, Y., Wang, J., et al. (2021). Deubiquitinase USP18 regulates reactive astrogliosis by stabilizing SOX9. Glia 69, 1782-1798. doi: 10.1002/glia.23992

Liu, X., Hunter, C., Weiss, H. R., and Chi, O. Z. (2010). Effects of blockade of ionotropic glutamate receptors on blood-brain barrier disruption in focal cerebral ischemia. Neurol. Sci. 31, 699-703. doi: 10.1007/s10072-010 -0241-5

Liu, W. L., Lee, Y. H., Tsai, S. Y., Hsu, C. Y., Sun, Y. Y., Yang, L. Y., et al. (2008). Methylprednisolone inhibits the expression of glial fibrillary acidic protein and chondroitin sulfate proteoglycans in reactivated astrocytes. Glia 56, 1390-1400. doi: 10.1002/glia.20706

Liu, T., Liao, X. Z., and Zhou, M. T. (2021). Ulinastatin alleviates traumatic brain injury by reducing endothelin-1. Transl. Neurosci. 12, 1-8. doi: 10.1515/tnsci2021-0001

Liu, W., Wang, Y., Gong, F., Rong, Y., Luo, Y., Tang, P., et al. (2019). Exosomes derived from bone mesenchymal stem cells repair traumatic spinal cord injury by suppressing the activation of A1 neurotoxic reactive astrocytes. J. Neurotrauma 36, 469-484. doi: 10.1089/neu.2018.5835

Liu, R., Wang, W., Wang, S., Xie, W., Li, H., and Ning, B. (2018). microRNA21 regulates astrocytic reaction post-acute phase of spinal cord injury through modulating TGF- $\beta$ signaling. Aging (Albany NY) 10, 1474-1488. doi: 10.18632/aging.101484

Liu, J., Yang, Y., and Liu, Y. (2021). Piezo1 plays a role in optic nerve head astrocyte reactivity. Exp. Eye Res. 204:108445. doi: 10.1016/j.exer.2021.108445

Long, X., Yao, X., Jiang, Q., Yang, Y., He, X., Tian, W., et al. (2020). Astrocytederived exosomes enriched with miR-873a-5p inhibit neuroinflammation via microglia phenotype modulation after traumatic brain injury. J. Neuroinflammation 17:89. doi: 10.1186/s12974-020-01761-0

Lööv, C., Hillered, L., Ebendal, T., and Erlandsson, A. (2012). Engulfing astrocytes protect neurons from contact-induced apoptosis following injury. PLoS One 7:e33090. doi: 10.1371/journal.pone.0033090

Lu, L., Hogan-Cann, A. D., Globa, A. K., Lu, P., Nagy, J. I., Bamji, S. X., et al. (2019). Astrocytes drive cortical vasodilatory signaling by activating endothelial NMDA receptors. J. Cereb. Blood Flow Metab. 39, 481-496. doi: 10.1177/0271678X17734100

Lu, Y., Sareddy, G. R., Wang, J., Zhang, Q., Tang, F. L., Pratap, U. P., et al. (2020). Neuron-derived estrogen is critical for astrocyte activation and neuroprotection of the ischemic brain. J. Neurosci. 40, 7355-7374. doi: 10.1523/JNEUROSCI.0115-20.2020

Lu, M., Yan, X. F., Si, Y., and Chen, X. Z. (2019). CTGF triggers rat astrocyte activation and astrocyte-mediated inflammatory response in culture conditions. Inflammation 42, 1693-1704. doi: 10.1007/s10753-019-01029-7

Lu, H., Zhan, Y., Ai, L., Chen, H., and Chen, J. (2020). AQP4-siRNA alleviates traumatic brain edema by altering post-traumatic AQP4 polarity reversal in TBI rats. J. Clin. Neurosci. 81, 113-119. doi: 10.1016/j.jocn.2020.09.015

Ma, M., Li, H., Wu, J., Zhang, Y., Shen, H., Li, X., et al. (2020). Roles of prokineticin 2 in subarachnoid hemorrhage-induced early brain injury via regulation of phenotype polarization in astrocytes. Mol. Neurobiol. 57, 3744-3758. doi: 10.1007/s12035-020-01990-7

Ma, E. L., Smith, A. D., Desai, N., Cheung, L., Hanscom, M., Stoica, B. A., et al. (2017). Bidirectional brain-gut interactions and chronic pathological changes after traumatic brain injury in mice. Brain Behav. Immun. 66, 56-69. doi: 10.1016/j.bbi.2017.06.018

Maas, A. I. R., Menon, D. K., Adelson, P. D., Andelic, N., Bell, M. J., Belli, A., et al. (2017). Traumatic brain injury: integrated approaches to improve prevention, clinical care and research. Lancet Neurol. 16, 987-1048. doi: 10.1016/S14744422(17)30371-X

Maas, A. I. R., Peul, W., and Thomé, C. (2021). Surgical decompression in acute spinal cord injury: earlier is better. Lancet Neurol. 20, 84-86. doi: 10.1016/S1474-4422(20)30478-6

Magavi, S., Friedmann, D., Banks, G., Stolfi, A., and Lois, C. (2012). Coincident generation of pyramidal neurons and protoplasmic astrocytes in neocortical columns. J. Neurosci. 32, 4762-4772. doi: 10.1523/JNEUROSCI.3560 $-11.2012$

Magnusson, J. P., Göritz, C., Tatarishvili, J., Dias, D. O., Smith, E. M., Lindvall, O., et al. (2014). A latent neurogenic program in astrocytes regulated by Notch signaling in the mouse. Science 346, 237-241. doi: 10.1126/science.346. 6206.237

Main, B. S., Villapol, S., Sloley, S. S., Barton, D. J., Parsadanian, M., Agbaegbu, C., et al. (2018). Apolipoprotein E4 impairs spontaneous blood brain barrier repair following traumatic brain injury. Mol. Neurodegener. 13:17. doi: 10.1186/s13024-018-0249-5

Manley, G. T., Fujimura, M., Ma, T., Noshita, N., Filiz, F., Bollen, A. W., et al. (2000). Aquaporin-4 deletion in mice reduces brain edema after acute water intoxication and ischemic stroke. Nat. Med. 6, 159-163. doi: 10.1038/ 72256

Matsuo, Y., Mihara, S., Ninomiya, M., and Fujimoto, M. (2001). Protective effect of endothelin type A receptor antagonist on brain edema and injury after transient middle cerebral artery occlusion in rats. Stroke 32, 2143-2148. doi: $10.1161 /$ hs0901.94259

McCarron, R. M., Wang, L., Stanimirovic, D. B., and Spatz, M. (1993). Endothelin induction of adhesion molecule expression on human brain microvascular endothelial cells. Neurosci. Lett. 156, 31-34. doi: 10.1016/0304-3940(93) 90432-k

Michinaga, S., Inoue, A., Sonoda, K., Mizuguchi, H., and Koyama, Y. (2021). Down-regulation of astrocytic sonic hedgehog by activation of endothelin ET(B) receptors: involvement in traumatic brain injury-induced disruption of blood brain barrier in a mouse model. Neurochem. Int. 146:105042. doi: 10.1016/j.neuint.2021.105042

Michinaga, S., Inoue, A., Yamamoto, H., Ryu, R., Inoue, A., Mizuguchi, H., et al. (2020a). Endothelin receptor antagonists alleviate blood-brain barrier disruption and cerebral edema in a mouse model of traumatic brain injury: a comparison between bosentan and ambrisentan. Neuropharmacology 175:108182. doi: 10.1016/j.neuropharm.2020.108182

Michinaga, S., Tanabe, A., Nakaya, R., Fukutome, C., Inoue, A., Iwane, A., et al. (2020b). Angiopoietin-1/Tie-2 signal after focal traumatic brain injury is potentiated by BQ788, an ET(B) receptor antagonist, in the mouse cerebrum: involvement in recovery of blood-brain barrier function. J. Neurochem. 154, 330-348. doi: 10.1111/jnc. 14957

Michinaga, S., Kimura, A., Hatanaka, S., Minami, S., Asano, A., Ikushima, Y. et al. (2018). Delayed administration of BQ788, an ET(B) antagonist, after experimental traumatic brain injury promotes recovery of blood-brain barrier function and a reduction of cerebral edema in mice. J. Neurotrauma 35, 1481-1494. doi: 10.1089/neu.2017.5421

Michinaga, S., and Koyama, Y. (2021). Pathophysiological responses and roles of astrocytes in traumatic brain injury. Int. J. Mol. Sci. 22:6418. doi: 10.3390/ijms22126418

Michinaga, S., and Koyama, Y. (2019). Dual roles of astrocyte-derived factors in regulation of blood-brain barrier function after brain damage. Int. J. Mol. Sci. 20:571. doi: 10.3390/ijms20030571

Miller, S. J. (2018). Astrocyte heterogeneity in the adult central nervous system. Front. Cell. Neurosci. 12:401. doi: 10.3389/fncel.2018.00401

Minkiewicz, J., de Rivero Vaccari, J. P., and Keane, R. W. (2013). Human astrocytes express a novel NLRP2 inflammasome. Glia 61, 1113-1121. doi: 10.1002/glia. 22499

Miyamoto, N., Magami, S., Inaba, T., Ueno, Y., Hira, K., Kijima, C., et al. (2020). The effects of A1/A2 astrocytes on oligodendrocyte linage cells against white matter injury under prolonged cerebral hypoperfusion. Glia 68, 1910-1924. doi: $10.1002 /$ glia.23814

Miyanji, F., Furlan, J. C., Aarabi, B., Arnold, P. M., and Fehlings, M. G. (2007). Acute cervical traumatic spinal cord injury: MR imaging findings correlated with neurologic outcome--prospective study with 100 consecutive patients. Radiology 243, 820-827. doi: 10.1148/radiol.2433060583 
Mizee, M. R., Nijland, P. G., van der Pol, S. M., Drexhage, J. A., van Het Hof, B., Mebius, R., et al. (2014). Astrocyte-derived retinoic acid: a novel regulator of blood-brain barrier function in multiple sclerosis. Acta Neuropathol. 128, 691-703. doi: 10.1007/s00401-014-1335-6

Molofsky, A. V., and Deneen, B. (2015). Astrocyte development: a guide for the perplexed. Glia 63, 1320-1329. doi: 10.1002/glia.22836

Montagne, A., Nation, D. A., Sagare, A. P., Barisano, G., Sweeney, M. D., Chakhoyan, A., et al. (2020). APOE4 leads to blood-brain barrier dysfunction predicting cognitive decline. Nature 581, 71-76. doi: 10.1038/s41586-020 $-2247-3$

Moon, L. D., and Fawcett, J. W. (2001). Reduction in CNS scar formation without concomitant increase in axon regeneration following treatment of adult rat brain with a combination of antibodies to TGFbeta 1 and beta2. Eur. J. Neurosci. 14, 1667-1677. doi: 10.1046/j.0953-816x.2001.01795.x

Morizawa, Y. M., Hirayama, Y., Ohno, N., Shibata, S., Shigetomi, E., Sui, Y., et al. (2017). Reactive astrocytes function as phagocytes after brain ischemia via ABCA1-mediated pathway. Nat. Commun. 8:28. doi: 10.1038/s41467-01700037-1

Myer, D. J., Gurkoff, G. G., Lee, S. M., Hovda, D. A., and Sofroniew, M. V. (2006). Essential protective roles of reactive astrocytes in traumatic brain injury. Brain 129, 2761-2772. doi: 10.1093/brain/awl165

Nakano, T., Nishigami, C., Irie, K., Shigemori, Y., Sano, K., Yamashita, Y., et al. (2018). Goreisan prevents brain edema after cerebral ischemic stroke by inhibiting aquaporin 4 upregulation in mice. J. Stroke Cerebrovasc. Dis. 27, 758-763. doi: 10.1016/j.jstrokecerebrovasdis.2017.10.010

Neal, M., Luo, J., Harischandra, D. S., Gordon, R., Sarkar, S., Jin, H., et al. (2018). Prokineticin-2 promotes chemotaxis and alternative $\mathrm{A} 2$ reactivity of astrocytes. Glia 66, 2137-2157. doi: 10.1002/glia.23467

Neary, J. T., Kang, Y., Tran, M., and Feld, J. (2005). Traumatic injury activates protein kinase B/Akt in cultured astrocytes: role of extracellular ATP and P2 purinergic receptors. J. Neurotrauma 22, 491-500. doi: 10.1089/neu.2005. 22.491

Neary, J. T., Kang, Y., Willoughby, K. A., and Ellis, E. F. (2003). Activation of extracellular signal-regulated kinase by stretch-induced injury in astrocytes involves extracellular ATP and P2 purinergic receptors. J. Neurosci. 23, 2348-2356. doi: 10.1523/JNEUROSCI.23-06-02348.2003

Nesic, O., Guest, J. D., Zivadinovic, D., Narayana, P. A., Herrera, J. J., Grill, R. J., et al. (2010). Aquaporins in spinal cord injury: the janus face of aquaporin 4. Neuroscience 168, 1019-1035. doi: 10.1016/j.neuroscience.2010. 01.037

Nesic, O., Lee, J., Unabia, G. C., Johnson, K., Ye, Z., Vergara, L., et al. (2008). Aquaporin 1 - a novel player in spinal cord injury. J. Neurochem. 105, 628-640. doi: $10.1111 / j .1471-4159.2007 .05177 . x$

Nesic, O., Lee, J., Ye, Z., Unabia, G. C., Rafati, D., Hulsebosch, C. E., et al. (2006). Acute and chronic changes in aquaporin 4 expression after spinal cord injury. Neuroscience 143, 779-792. doi: 10.1016/j.neuroscience.2006.08.079

Nishiyama, A., Boshans, L., Goncalves, C. M., Wegrzyn, J., and Patel, K. D. (2016). Lineage, fate and fate potential of NG2-glia. Brain Res. 1638, 116-128. doi: 10.1016/j.brainres.2015.08.013

Niu, W., Zang, T., Zou, Y., Fang, S., Smith, D. K., Bachoo, R., et al. (2013). in vivo reprogramming of astrocytes to neuroblasts in the adult brain. Nat. Cell Biol. 15, 1164-1175. doi: 10.1038/ncb2843

Noble, L. J., Donovan, F., Igarashi, T., Goussev, S., and Werb, Z. (2002). Matrix metalloproteinases limit functional recovery after spinal cord injury by modulation of early vascular events. J. Neurosci. 22, 7526-7535. doi: 10.1523/JNEUROSCI.22-17-07526.2002

Noristani, H. N., Sabourin, J. C., Boukhaddaoui, H., Chan-Seng, E., Gerber, Y. N., and Perrin, F. E. (2016). Spinal cord injury induces astroglial conversion towards neuronal lineage. Mol. Neurodegener. 11:68. doi: 10.1186/s13024-0160133-0

Oliva, A. A., Jr., Kang, Y., Sanchez-Molano, J., Furones, C., and Atkins, C. M. (2012). STAT3 signaling after traumatic brain injury. J. Neurochem. 120, 710-720. doi: 10.1111/j.1471-4159.2011.07610.x.

O’Neill, L. A., and Kaltschmidt, C. (1997). NF-kappa B: a crucial transcription factor for glial and neuronal cell function. Trends Neurosci. 20, 252-258. doi: 10.1016/s0166-2236(96)01035-1

O'Shea, T. M., Burda, J. E., and Sofroniew, M. V. (2017). Cell biology of spinal cord injury and repair. J. Clin. Invest. 127, 3259-3270. doi: 10.1172/JCI90608
Oyinbo, C. A. (2011). Secondary injury mechanisms in traumatic spinal cord injury: a nugget of this multiply cascade. Acta Neurobiol. Exp. (Wars) 71, 281-299.

Pardo, L., Schlüter, A., Valor, L. M., Barco, A., Giralt, M., Golbano, A., et al. (2016). Targeted activation of CREB in reactive astrocytes is neuroprotective in focal acute cortical injury. Glia 64, 853-874. doi: 10.1002/glia.22969

Patil, V., O'Connell, E., Quinlan, L. R., Fearnhead, H., McMahon, S., and Pandit, A. (2021). A robust platform for high-throughput screening of therapeutic strategies for acute and chronic spinal cord injury. iScience 24:102182. doi: 10.1016/j.isci.2021.102182

Pei, D., Liu, N., Li, D., Yan, H., Wang, Q. B., Fang, Y., et al. (2017). Inhibition of platelet-derived growth factor receptor $\beta$ reduces reactive glia and scar formation after traumatic brain injury in mice. Brain Res. Bull. 134, 121-127. doi: 10.1016/j.brainresbull.2017.06.020

Pekny, M., Johansson, C. B., Eliasson, C., Stakeberg, J., Wallén, A., Perlmann, T., et al. (1999). Abnormal reaction to central nervous system injury in mice lacking glial fibrillary acidic protein and vimentin. J. Cell Biol. 145, 503-514. doi: $10.1083 /$ jcb.145.3.503

Pitt, J., Wilcox, K. C., Tortelli, V., Diniz, L. P., Oliveira, M. S., Dobbins, C., et al. (2017). Neuroprotective astrocyte-derived insulin/insulin-like growth factor 1 stimulates endocytic processing and extracellular release of neuronbound A $\beta$ oligomers. Mol. Biol. Cell 28, 2623-2636. doi: 10.1091/mbc.E1706-0416

Popovich, P. G., and Jones, T. B. (2003). Manipulating neuroinflammatory reactions in the injured spinal cord: back to basics. Trends Pharmacol. Sci. 24, 13-17. doi: 10.1016/s0165-6147(02)00006-8

Pozo-Rodrigálvarez, A., Ollaranta, R., Skoog, J., Pekny, M., and Pekna, M. (2021). Hyperactive behavior and altered brain morphology in adult complement C3a receptor deficient mice. Front. Immunol. 12:604812. doi: 10.3389/fimmu.2021. 604812

Puls, B., Ding, Y., Zhang, F., Pan, M., Lei, Z., Pei, Z., et al. (2020). Regeneration of functional neurons after spinal cord injury via in situ neuroD1mediated astrocyte-to-neuron conversion. Front. Cell Dev. Biol. 8:591883. doi: $10.3389 /$ fcell.2020.591883

Qian, F., Han, Y., Han, Z., Zhang, D., Zhang, L., Zhao, G., et al. (2021). in situ implantable, post-trauma microenvironment-responsive, ROS depletion hydrogels for the treatment of traumatic brain injury. Biomaterials 270:120675. doi: 10.1016/j.biomaterials.2021.120675

Qian, D., Li, L., Rong, Y., Liu, W., Wang, Q., Zhou, Z., et al. (2019). Blocking notch signal pathway suppresses the activation of neurotoxic Al astrocytes after spinal cord injury. Cell Cycle 18, 3010-3029. doi: 10.1080/15384101.2019. 1667189

Ren, Y. Z., Zhang, B. Z., Zhao, X. J., and Zhang, Z. Y. (2020). Resolvin D1 ameliorates cognitive impairment following traumatic brain injury via protecting astrocytic mitochondria. J. Neurochem. 154, 530-546. doi: $10.1111 /$ jnc. 14962

Ribeiro, T. N., Delgado-García, L. M., and Porcionatto, M. A. (2021). Notch1 and galectin-3 modulate cortical reactive astrocyte response after brain injury. Front. Cell Dev. Biol. 9:649854. doi: 10.3389/fcell.2021.649854

Rolls, A., Shechter, R., and Schwartz, M. (2009). The bright side of the glial scar in CNS repair. Nat. Rev. Neurosci. 10, 235-241. doi: 10.1038/ nrn2591

Ronnevi, L. O. (1978). Origin of the glial processes responsible for the spontaneous postnatal phagocytosis of boutons on cat spinal motoneurons. Cell Tissue Res. 189, 203-217. doi: 10.1007/BF00209270

Rosciszewski, G., Cadena, V., Murta, V., Lukin, J., Villarreal, A., Roger, T., et al. (2018). Toll-like receptor 4 (TLR4) and triggering receptor expressed on myeloid cells-2 (TREM-2) activation balance astrocyte polarization into a proinflammatory phenotype. Mol. Neurobiol. 55, 3875-3888. doi: 10.1007/s12035-017-0618-z

Rui, Q., Ni, H., Lin, X., Zhu, X., Li, D., Liu, H., et al. (2019). Astrocyte-derived fatty acid-binding protein 7 protects blood-brain barrier integrity through a caveolin-1/MMP signaling pathway following traumatic brain injury. Exp. Neurol. 322:113044. doi: 10.1016/j.expneurol.2019.113044

Saadoun, S., Bell, B. A., Verkman, A. S., and Papadopoulos, M. C. (2008), Greatly improved neurological outcome after spinal cord compression injury in AQP4-deficient mice. Brain 131, 1087-1098. doi: 10.1093/brain/ awn014 
Saadoun, S., and Papadopoulos, M. C. (2010). Aquaporin-4 in brain and spinal cord oedema. Neuroscience 168, 1036-1046. doi: 10.1016/j.neuroscience.2009. 08.019

Sabirzhanov, B., Matyas, J., Coll-Miro, M., Yu, L. L., Faden, A. I., Stoica, B. A., et al. (2019). Inhibition of microRNA-711 limits angiopoietin-1 and Akt changes, tissue damage and motor dysfunction after contusive spinal cord injury in mice. Cell Death Dis. 10:839. doi: 10.1038/s41419-019-2079-y

Saha, R. N., and Pahan, K. (2006). Signals for the induction of nitric oxide synthase in astrocytes. Neurochem. Int. 49, 154-163. doi: 10.1016/j.neuint.2006. 04.007

Schachtrup, C., Ryu, J. K., Helmrick, M. J., Vagena, E., Galanakis, D. K., Degen, J. L., et al. (2010). Fibrinogen triggers astrocyte scar formation by promoting the availability of active TGF-beta after vascular damage. J. Neurosci. 30, 5843-5854. doi: 10.1523/JNEUROSCI.0137-10.2010

Schiweck, J., Murk, K., Ledderose, J., Münster-Wandowski, A., Ornaghi, M., Vida, I., et al. (2021). Drebrin controls scar formation and astrocyte reactivity upon traumatic brain injury by regulating membrane trafficking. Nat. Commun. 12:1490. doi: 10.1038/s41467-021-21662-x

Schneider, A., Martin-Villalba, A., Weih, F., Vogel, J., Wirth, T., and Schwaninger, M. (1999). NF-kappaB is activated and promotes cell death in focal cerebral ischemia. Nat. Med. 5, 554-559. doi: 10.1038/8432

Senbokuya, N., Yoshioka, H., Yagi, T., Owada, Y., and Kinouchi, H. (2019). Effects of FABP7 on functional recovery after spinal cord injury in adult mice. J. Neurosurg. Spine 31, 1-7. doi: 10.3171/2019.2.SPINE18844

Sharma, H. S., Badgaiyan, R. D., Alm, P., Mohanty, S., and Wiklund, L. (2005). Neuroprotective effects of nitric oxide synthase inhibitors in spinal cord injury-induced pathophysiology and motor functions: an experimental study in the rat. Ann. N Y Acad. Sci. 1053, 422-434. doi: 10.1111/j.1749-6632.2005. tb00051.x

Sharma, H. S., Feng, L., Muresanu, D. F., Castellani, R. J., and Sharma, A. (2019). Neuroprotective effects of a potent bradykinin B2 receptor antagonist HOE-140 on microvascular permeability, blood flow disturbances, edema formation, cell injury and nitric oxide synthase upregulation following trauma to the spinal cord. Int. Rev. Neurobiol. 146, 103-152. doi: 10.1016/bs.irn.2019. 06.008

Shinozaki, Y., Shibata, K., Yoshida, K., Shigetomi, E., Gachet, C., Ikenaka, K., et al. (2017). Transformation of astrocytes to a neuroprotective phenotype by microglia via P2Y(1) receptor downregulation. Cell Rep. 19, 1151-1164. doi: 10.1016/j.celrep.2017.04.047

Shiow, L. R., Favrais, G., Schirmer, L., Schang, A. L., Cipriani, S., Andres, C., et al. (2017). Reactive astrocyte COX2-PGE2 production inhibits oligodendrocyte maturation in neonatal white matter injury. Glia 65, 2024-2037. doi: 10.1002/glia.23212

Siebert, J. R., Stelzner, D. J., and Osterhout, D. J. (2011). Chondroitinase treatment following spinal contusion injury increases migration of oligodendrocyte progenitor cells. Exp. Neurol. 231, 19-29. doi: 10.1016/j.expneurol.2011.05.002

Silver, J., and Miller, J. H. (2004). Regeneration beyond the glial scar. Nat. Rev. Neurosci. 5, 146-156. doi: 10.1038/nrn1326

Skandsen, T., Kvistad, K. A., Solheim, O., Strand, I. H., Folvik, M., and Vik, A. (2010). Prevalence and impact of diffuse axonal injury in patients with moderate and severe head injury: a cohort study of early magnetic resonance imaging findings and 1-year outcome. J. Neurosurg. 113, 556-563. doi: 10.3171/2009.9.JNS09626

Smith, P. D., Coulson-Thomas, V. J., Foscarin, S., Kwok, J. C., and Fawcett, J. W. (2015). "GAG-ing with the neuron": the role of glycosaminoglycan patterning in the central nervous system. Exp. Neurol. 274, 100-114. doi: 10.1016/j. expneurol.2015.08.004

Smith, D. C., Modglin, A. A., Roosevelt, R. W., Neese, S. L., Jensen, R. A., Browning, R. A., et al. (2005). Electrical stimulation of the vagus nerve enhances cognitive and motor recovery following moderate fluid percussion injury in the rat. J. Neurotrauma 22, 1485-1502. doi: 10.1089/neu.2005.22.1485

Sofroniew, M. V. (2015). Astrocyte barriers to neurotoxic inflammation. Nat. Rev. Neurosci. 16, 249-263. doi: 10.1038/nrn3898

Sofroniew, M. V. (2018). Dissecting spinal cord regeneration. Nature 557, 343-350. doi: 10.1038/s41586-018-0068-4

Song, Y., Cao, C., Xu, Q., Gu, S., Wang, F., Huang, X., et al. (2020). Piperine attenuates TBI-induced seizures via inhibiting cytokine-activated reactive astrogliosis. Front. Neurol. 11:431. doi: 10.3389/fneur.2020.00431
Song, X., Gong, Z., Liu, K., Kou, J., Liu, B., and Liu, K. (2020). Baicalin combats glutamate excitotoxicity via protecting glutamine synthetase from ROS-induced 20S proteasomal degradation. Redox. Biol. 34:101559. doi: 10.1016/j.redox.2020.101559

Sticozzi, C., Belmonte, G., Meini, A., Carbotti, P., Grasso, G., and Palmi, M. (2013). IL-1 $\beta$ induces GFAP expression in vitro and in vivo and protects neurons from traumatic injury-associated apoptosis in rat brain striatum via $\mathrm{NF \kappa} B / \mathrm{Ca}^{2}$-calmodulin/ERK mitogen-activated protein kinase signaling pathway. Neuroscience 252, 367-383. doi: 10.1016/j.neuroscience.2013. 07.061

Struve, J., Maher, P. C., Li, Y. Q., Kinney, S., Fehlings, M. G., Kuntz 4th, C., et al. (2005). Disruption of the hyaluronan-based extracellular matrix in spinal cord promotes astrocyte proliferation. Glia 52, 16-24. doi: 10.1002/glia.20215

Su, Y., Chen, Z., Du, H., Liu, R., Wang, W., Li, H., et al. (2019). Silencing miR-21 induces polarization of astrocytes to the A2 phenotype and improves the formation of synapses by targeting glypican 6 via the signal transducer and activator of transcription-3 pathway after acute ischemic spinal cord injury. FASEB J. 33, 10859-10871. doi: 10.1096/fj.201900743R

Su, Z., Niu, W., Liu, M. L., Zou, Y., and Zhang, C. L. (2014). in vivo conversion of astrocytes to neurons in the injured adult spinal cord. Nat. Commun. 5:3338. doi: $10.1038 /$ ncomms4338

Su, Y., Wang, Y., Zhou, Y., Zhu, Z., Zhang, Q., Zhang, X., et al. (2017). Macrophage migration inhibitory factor activates inflammatory responses of astrocytes through interaction with CD74 receptor. Oncotarget 8, 2719-2730. doi: 10.18632 /oncotarget.13739

Sulejczak, D., Taraszewska, A., Chrapusta, S. J., Dziewulska, D., Nakielski, P., and Rafaowska, J. (2016). Nanofiber mat spinal cord dressing-released glutamate impairs blood-spinal cord barrier. Folia Neuropathol. 54, 392-404. doi: $10.5114 /$ fn. 2016.64818

Sulimai, N., Brown, J., and Lominadze, D. (2021). Fibrinogen interaction with astrocyte ICAM-1 and $\operatorname{PrP}(\mathrm{C})$ results in the generation of ROS and neuronal death. Int. J. Mol. Sci. 22:2391. doi: 10.3390/ijms22052391

Sun, L., Li, M., Ma, X., Feng, H., Song, J., Lv, C., et al. (2017). Inhibition of HMGB1 reduces rat spinal cord astrocytic swelling and AQP4 expression after oxygen-glucose deprivation and reoxygenation via TLR4 and NF$\mathrm{B}$ signaling in an IL-6-dependent manner. J. Neuroinflammation 14:231. doi: 10.1186/s12974-017-1008-1

Sun, L., Li, M., Ma, X., Zhang, L., Song, J., Lv, C., et al. (2019). Inhibiting high mobility group box-1 reduces early spinal cord edema and attenuates astrocyte activation and aquaporin-4 expression after spinal cord injury in rats. J. Neurotrauma 36, 421-435. doi: 10.1089/neu.2018.5642

Sun, J. D., Zeng, Y. H., Zhang, Y., Yang, X. X., Zeng, W. J., Zhao, L. S., et al. (2019). MiR-325-3p promotes locomotor function recovery in rats with spinal cord injury via inhibiting the expression of neutrophil elastase. Eur. Rev. Med. Pharmacol.Sci. 23, 10631-10637. doi: 10.26355/eurrev_201912_19760

Susarla, B. T., Villapol, S., Yi, J. H., Geller, H. M., and Symes, A. J. (2014). Temporal patterns of cortical proliferation of glial cell populations after traumatic brain injury in mice. ASN Neuro. 6, 159-170. doi: 10.1042/AN20130034

Swanson, R. A., Ying, W., and Kauppinen, T. M. (2004). Astrocyte influences on ischemic neuronal death. Curr. Mol. Med. 4, 193-205. doi: 10.2174/1566524043479185

Tait, M. J., Saadoun, S., Bell, B. A., and Papadopoulos, M. C. (2008). Water movements in the brain: role of aquaporins. Trends Neurosci. 31, 37-43. doi: 10.1016/j.tins.2007.11.003

Talley Watts, L., Sprague, S., Zheng, W., Garling, R. J., Jimenez, D., Digicaylioglu, M., et al. (2013). Purinergic 2Y1 receptor stimulation decreases cerebral edema and reactive gliosis in a traumatic brain injury model. J. Neurotrauma 30, 55-66. doi: 10.1089/neu.2012.2488

Taylor, C. A., Bell, J. M., Breiding, M. J., and Xu, L. (2017). Traumatic brain injuryrelated emergency department visits, hospitalizations and deaths - United States, 2007 and 2013. MMWR Surveill. Summ. 66, 1-16. doi: 10.15585/mmwr. ss6609a1

Teh, D. B. L., Prasad, A., Jiang, W., Ariffin, M. Z., Khanna, S., Belorkar, A. et al. (2017). Transcriptome analysis reveals neuroprotective aspects of human reactive astrocytes induced by interleukin 1B. Sci. Rep. 7:13988. doi: 10.1038/s41598-017-13174-w

Torper, O., Pfisterer, U., Wolf, D. A., Pereira, M., Lau, S., Jakobsson, J., et al. (2013). Generation of induced neurons via direct conversion in vivo. 
Proc. Natl. Acad. Sci. U S A 110, 7038-7043. doi: 10.1073/pnas.1303 829110

Tran, A. P., Warren, P. M., and Silver, J. (2018). The biology of regeneration failure and success after spinal cord injury. Physiol. Rev. 98, 881-917. doi: 10.1152/physrev.00017.2017

Tsai, H. H., Li, H., Fuentealba, L. C., Molofsky, A. V., Taveira-Marques, R., Zhuang, H., et al. (2012). Regional astrocyte allocation regulates CNS synaptogenesis and repair. Science 337, 358-362. doi: 10.1126/science.1222381

Tu, Z., Li, Y., Dai, Y., Li, L., Lv, G., Chen, I., et al. (2017). MiR-140/BDNF axis regulates normal human astrocyte proliferation and LPS-induced IL-6 and TNF- $\alpha$ secretion. Biomed. Pharmacother. 91, 899-905. doi: 10.1016/j.biopha. 2017.05.016

Valori, C. F., Guidotti, G., Brambilla, L., and Rossi, D. (2019). Astrocytes: emerging therapeutic targets in neurological disorders. Trends Mol. Med. 25, 750-759. doi: 10.1016/j.molmed.2019.04.010

Verkhratsky, A., and Nedergaard, M. (2018). Physiology of astroglia. Physiol. Rev. 98, 239-389. doi: 10.1152/physrev.00042.2016

Villapol, S., Byrnes, K. R., and Symes, A. J. (2014). Temporal dynamics of cerebral blood flow, cortical damage, apoptosis, astrocyte-vasculature interaction and astrogliosis in the pericontusional region after traumatic brain injury. Front. Neurol. 5:82. doi: 10.3389/fneur.2014.00082

Virchow, R. (1856). Gesammelte abhandlungen zur wissenschaftlichen Medicin. Frankfurt: Meidinger Sohn \& Comp.

Vismara, I., Papa, S., Veneruso, V., Mauri, E., Mariani, A., De Paola, M., et al. (2020). Selective modulation of A1 astrocytes by drug-loaded nano-structured gel in spinal cord injury. ACS Nano 14, 360-371. doi: 10.1021/acsnano.9b05579

Voskuhl, R. R., Peterson, R. S., Song, B., Ao, Y., Morales, L. B., TiwariWoodruff, S., et al. (2009). Reactive astrocytes form scar-like perivascular barriers to leukocytes during adaptive immune inflammation of the CNS. J. Neurosci. 29, 11511-11522. doi: 10.1523/JNEUROSCI.1514-09.2009

Wakida, N. M., Cruz, G. M. S., Pouladian, P., Berns, M. W., and Preece, D. (2020). Fluid shear stress enhances the phagocytic response of astrocytes. Front. Bioeng. Biotechnol. 8:596577. doi: 10.3389/fbioe.2020.596577

Wang, S., Deng, J., Fu, H., Guo, Z., Zhang, L., and Tang, P. (2020). Astrocytes directly clear myelin debris through endocytosis pathways and followed by excessive gliosis after spinal cord injury. Biochem. Biophys. Res. Commun. [Online ahead of print]. doi: 10.1016/j.bbrc.2020.02.069

Wang, J., Hou, Y., Zhang, L., Liu, M., Zhao, J., Zhang, Z., et al. (2021). Estrogen attenuates traumatic brain injury by inhibiting the activation of microglia and astrocyte-mediated neuroinflammatory responses. Mol. Neurobiol. 58, 1052-1061. doi: 10.1007/s12035-020-02171-2

Wang, K., Liu, B., and Ma, J. (2014). Research progress in traumatic brain penumbra. Chin. Med. J. (Engl) 127, 1964-1968. doi: 10.3760/cma.j.issn.03666999.20120638

Wang, L., Pei, S., Han, L., Guo, B., Li, Y., Duan, R., et al. (2018). Mesenchymal stem cell-derived exosomes reduce A1 astrocytes via downregulation of phosphorylated NFкB P65 subunit in spinal cord injury. Cell. Physiol. Biochem. 50, 1535-1559. doi: 10.1159/000494652

Wang, J., Sareddy, G. R., Lu, Y., Pratap, U. P., Tang, F., Greene, K. M., et al. (2020). Astrocyte-derived estrogen regulates reactive astrogliosis and is neuroprotective following ischemic brain injury. J. Neurosci. 40, 9751-9771. doi: 10.1523/JNEUROSCI.0888-20.2020

Wang, C. Y., Yang, S. H., and Tzeng, S. F. (2015). MicroRNA-145 as one negative regulator of astrogliosis. Glia 63, 194-205. doi: 10.1002/glia.22743

Wicher, G., Wallenquist, U., Lei, Y., Enoksson, M., Li, X., Fuchs, B., et al. (2017). Interleukin-33 promotes recruitment of microglia/macrophages in response to traumatic brain injury. J. Neurotrauma 34, 3173-3182. doi: 10.1089/neu.2016. 4900

Wu, H., Mahmood, A., Lu, D., Jiang, H., Xiong, Y., Zhou, D., et al. (2010). Attenuation of astrogliosis and modulation of endothelial growth factor receptor in lipid rafts by simvastatin after traumatic brain injury. J. Neurosurg. 113, 591-597. doi: 10.3171/2009.9.JNS09859

Xia, Y. P., He, Q. W., Li, Y. N., Chen, S. C., Huang, M., Wang, Y., et al. (2013). Recombinant human sonic hedgehog protein regulates the expression of ZO-1 and occludin by activating angiopoietin-1 in stroke damage. PLoS One 8:e68891. doi: 10.1371/journal.pone.0068891

Xia, X., Ma, Y., Yang, L. B., Cheng, J. M., Yang, T., Fan, K. X., et al. (2016). Impact of heat shock protein A 12B overexpression on spinal astrocyte survival against oxygen-glucose-serum deprivation/restoration in primary cultured astrocytes J. Mol. Neurosci. 59, 511-520. doi: 10.1007/s12031-016-0768-x

Xing, G., Zhao, T., Zhang, X., Li, H., Li, X., Cui, P., et al. (2020). Astrocytic sonic hedgehog alleviates intracerebral hemorrhagic brain injury via modulation of blood-brain barrier integrity. Front. Cell. Neurosci. 14:575690. doi: $10.3389 /$ fncel.2020.575690

Xu, X., Zhang, A., Zhu, Y., He, W., Di, W., Fang, Y., et al. (2018) MFG-E8 reverses microglial-induced neurotoxic astrocyte (A1) via NF- $\mathrm{B}$ and PI3K-Akt pathways. J. Cell Physiol. 234, 904-914. doi: 10.1002/jcp. 26918

Yadav, S. K., Ito, N., Soin, D., Ito, K., and Dhib-Jalbut, S. (2021). Dimethyl fumarate suppresses demyelination and axonal loss through reduction in pro-inflammatory macrophage-induced reactive astrocytes and complement C3 deposition. J. Clin. Med. 10:857. doi: 10.3390/jcm10040857

Yang, H., Liu, C., Fan, H., Chen, B., Huang, D., Zhang, L., et al. (2019). Sonic hedgehog effectively improves Oct4-mediated reprogramming of astrocytes into neural stem cells. Mol. Ther. 27, 1467-1482. doi: 10.1016/j.ymthe.2019. 05.006

Yang, J., Vitery, M. D. C., Chen, J., Osei-Owusu, J., Chu, J., and Qiu, Z. (2019). Glutamate-releasing sWELL1 channel in astrocytes modulates synaptic transmission and promotes brain damage in stroke. Neuron 102, 813-827.e6. doi: 10.1016/j.neuron.2019.03.029

Yang, J., Shao, C., Li, W., Wan, H., He, Y., and Yang, J. (2021). Protective effects of Astragaloside IV against oxidative injury and apoptosis in cultured astrocytes by regulating Nrf2/JNK signaling. Exp. Brain Res. 239, 1827-1840. doi: 10.1007/s00221-021-06096-7

Yang, Y., Yi, J., Pan, M., Hu, B., and Duan, H. (2021). Edaravone alleviated propofol-induced neural injury in developing rats by BDNF/TrkB pathway. J. Cell Mol. Med. 25, 4974-4987. doi: 10.1111/jcmm.16422

Yao, X., Wang, S., Chen, Y., Sheng, L., Li, H., You, H., et al. (2021). Sodium houttuyfonate attenuates neurological defects after traumatic brain injury in mice via inhibiting NLRP3 inflammasomes. J. Biochem. Mol. Toxicol. 35:e22850. doi: 10.1002/jbt.22850

You, T., Bi, Y., Li, J., Zhang, M., Chen, X., Zhang, K., et al. (2017). IL17 induces reactive astrocytes and up-regulation of vascular endothelial growth factor (VEGF) through JAK/STAT signaling. Sci. Rep. 7:41779. doi: $10.1038 /$ srep41779

Yue, Y., Zhao, J., Li, X., Zhang, L., Su, Y., and Fan, H. (2020). Involvement of Shh/Glil signaling in the permeability of blood-spinal cord barrier and locomotion recovery after spinal cord contusion. Neurosci. Lett. 728:134947. doi: 10.1016/j.neulet.2020.134947

Yun, S. P., Kam, T. I., Panicker, N., Kim, S., Oh, Y., Park, J. S., et al. (2018). Block of A1 astrocyte conversion by microglia is neuroprotective in models of Parkinson's disease. Nat. Med. 24, 931-938. doi: 10.1038/s41591-018-0051-5

Zaheer, A., Yorek, M. A., and Lim, R. (2001). Effects of glia maturation factor overexpression in primary astrocytes on MAP kinase activation, transcription factor activation and neurotrophin secretion. Neurochem. Res. 26, 1293-1299. doi: 10.1023/a:1014241300179

Zamanian, J. L., Xu, L., Foo, L. C., Nouri, N., Zhou, L., Giffard, R. G., et al. (2012). Genomic analysis of reactive astrogliosis. J. Neurosci. 32, 6391-6410. doi: 10.1523/JNEUROSCI.6221-11.2012

Zamora, N. N., Cheli, V. T., Santiago González, D. A., Wan, R., and Paez, P. M. (2020). Deletion of voltage-gated calcium channels in astrocytes during demyelination reduces brain inflammation and promotes myelin regeneration in mice. J. Neurosci. 40, 3332-3347. doi: 10.1523/JNEUROSCI.1644 $-19.2020$

Zarei-Kheirabadi, M., Hesaraki, M., Kiani, S., and Baharvand, H. (2019a). In vivo conversion of rat astrocytes into neuronal cells through neural stem cells in injured spinal cord with a single zinc-finger transcription factor. Stem Cell Res. Ther. 10:380. doi: 10.1186/s13287-019-1448-x

Zarei-Kheirabadi, M., Hesaraki, M., Shojaei, A., Kiani, S., and Baharvand, H. (2019b). Generation of neural stem cells from adult astrocytes by using a single reprogramming factor. J. Cell Physiol. 234, 18697-18706. doi: 10.1002/jcp. 28510

Zhang, L., Guo, K., Zhou, J., Zhang, X., Yin, S., Peng, J., et al. (2021) Ponesimod protects against neuronal death by suppressing the activation of A1 astrocytes in early brain injury after experimental subarachnoid hemorrhage. J. Neurochem. 158, 880-897. doi: 10.1111/jnc.15457 
Zhang, Z. W., Liang, J., Yan, J. X., Ye, Y. C., Wang, J. J., Chen, C., et al. (2020). TBHQ improved neurological recovery after traumatic brain injury by inhibiting the overactivation of astrocytes. Brain Res. 1739:146818. doi: 10.1016/j.brainres.2020.146818

Zhang, D., Lu, Z., Man, J., Cui, K., Fu, X., Yu, L., et al. (2019). Wnt-3a alleviates neuroinflammation after ischemic stroke by modulating the responses of microglia/macrophages and astrocytes. Int. Immunopharmacol. 75:105760. doi: 10.1016/j.intimp.2019.105760

Zhang, Z., Ma, Z., Yan, C., Pu, K., Wu, M., Bai, J., et al. (2019). Muscle-derived autologous mitochondrial transplantation: a novel strategy for treating cerebral ischemic injury. Behav. Brain Res. 356, 322-331. doi: 10.1016/j.bbr.2018. 09.005

Zhang, Y., Sloan, S. A., Clarke, L. E., Caneda, C., Plaza, C. A., Blumenthal, P. D., et al. (2016). Purification and characterization of progenitor and mature human astrocytes reveals transcriptional and functional differences with mouse. Neuron 89, 37-53. doi: 10.1016/j.neuron.2015. 11.013

Zhang, P., Sun, H., and Ji, Z. (2021). Downregulating lncRNA PVT1 relieves astrocyte overactivation induced neuropathic pain through targeting miR-186-5p/CXCL13/CXCR5 axis. Neurochem. Res. 46, 1457-1469. doi: 10.1007/s11064-021-03287-0

Zhang, X., Zhang, Q., Huang, L., Liu, M., Cheng, Z., Zheng, Y., et al. (2021). PienTze-Huang attenuates neuroinflammation in cerebral ischaemia-reperfusion injury in rats through the TLR4/NF-кB/MAPK pathway. Pharm. Biol. 59, 828-839. doi: 10.1080/13880209.2021.1942926

Zhang, Y., Wang, J., Zhang, Y., Wei, J., Wu, R., and Cai, H. (2019a). Overexpression of long noncoding RNA Malat1 ameliorates traumatic brain injury induced brain edema by inhibiting AQP4 and the NF- $\mathrm{B} / \mathrm{IL}-6$ pathway. J. Cell Biochem. 120, 17584-17592. doi: 10.1002/jcb.29025

Zhang, Y., Zhou, Y., Chen, S., Hu, Y., Zhu, Z., Wang, Y., et al. (2019b). Macrophage migration inhibitory factor facilitates prostaglandin $\mathrm{E}(2)$ production of astrocytes to tune inflammatory milieu following spinal cord injury. J. Neuroinflammation 16:85. doi: 10.1186/s12974-019-1468-6

Zheng, J., Lu, J., Mei, S., Wu, H., Sun, Z., Fang, Y., et al. (2021). Ceria nanoparticles ameliorate white matter injury after intracerebral hemorrhage: microglia-astrocyte involvement in remyelination. J. Neuroinflammation 18:43 doi: 10.1186/s12974-021-02101-6

Zhou, Y., Guo, W., Zhu, Z., Hu, Y., Wang, Y., Zhang, X., et al. (2018). Macrophage migration inhibitory factor facilitates production of CCL5 in astrocytes following rat spinal cord injury. J. Neuroinflammation 15:253. doi: 10.1186/s12974-018-1297-Z

Zhou, Y., Zhang, H., Zheng, B., Ye, L., Zhu, S., Johnson, N. R., et al. (2016). Retinoic acid induced-autophagic flux inhibits ER-stress dependent apoptosis and prevents disruption of blood-spinal cord barrier after spinal cord injury. Int. J. Biol. Sci. 12, 87-99. doi: 10.7150/ijbs.13229

Zong, X., Li, Y., Liu, C., Qi, W., Han, D., Tucker, L., et al. (2020). Theta-burst transcranial magnetic stimulation promotes stroke recovery by vascular protection and neovascularization. Theranostics 10, 12090-12110. doi: 10.7150/thno.51573

Zou, L. H., Shi, Y. J., He, H., Jiang, S. M., Huo, F. F., Wang, X. M., et al. (2019). Effects of FGF2/FGFR1 pathway on expression of A1 astrocytes after infrasound exposure. Front. Neurosci. 13:429. doi: 10.3389/fnins.2019. 00429

Conflict of Interest: The authors declare that the research was conducted in the absence of any commercial or financial relationships that could be construed as a potential conflict of interest.

Publisher's Note: All claims expressed in this article are solely those of the authors and do not necessarily represent those of their affiliated organizations, or those of the publisher, the editors and the reviewers. Any product that may be evaluated in this article, or claim that may be made by its manufacturer, is not guaranteed or endorsed by the publisher.

Copyright (c) $2021 \mathrm{Yu}$, Zhang and Ning. This is an open-access article distributed under the terms of the Creative Commons Attribution License (CC BY). The use, distribution or reproduction in other forums is permitted, provided the original author(s) and the copyright owner(s) are credited and that the original publication in this journal is cited, in accordance with accepted academic practice. No use, distribution or reproduction is permitted which does not comply with these terms. 